\title{
Formation mechanisms for self-organized km-scale shoreline sand waves
}

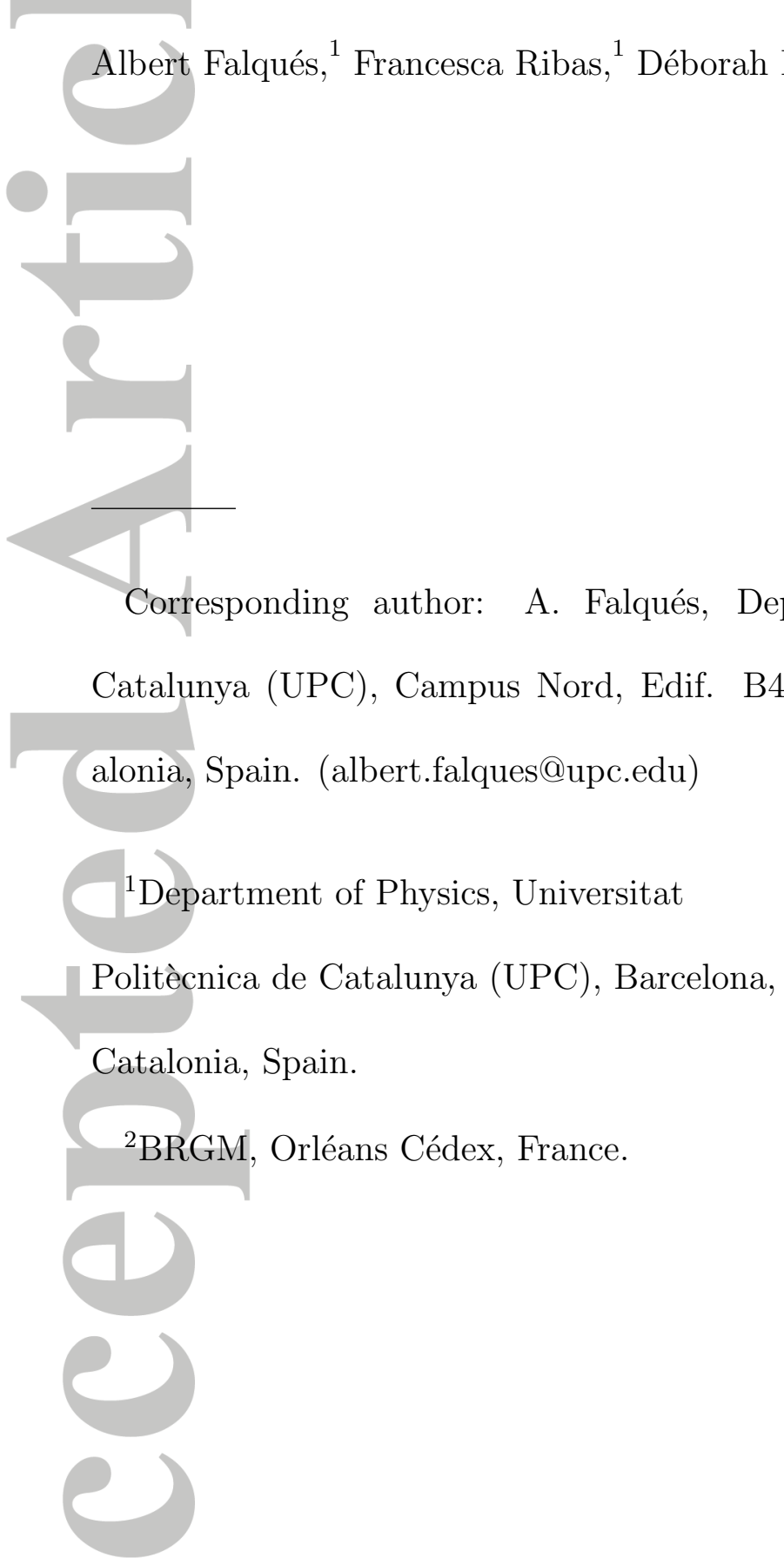

This article has been accepted for publication and undergone full peer review but has not been through the copyediting, typesetting, pagination and proofreading process, which may lead to differences between this version and the Version of Record. Please cite this article as doi: 10.1002/2016JF003964

(C)2017 American Geophysical Union. All Rights Reserved. 
Abstract. The feedbacks between morphology and waves through the sediment transport are investigated as a source of km-scale shoreline sand waves. In particular, the observed sand waves along Srd. Holmslands Tange, Denmark, are examined. We use a linear stability model based on the oneline approximation, linking the bathymetry to the perturbed shoreline. Previous models that consider the link by shifting the equilibrium profile and

neglecting the curvature of the depth contours predict a positive feedback only if the offshore wave incidence angle $\left(\theta_{c}\right)$ is above a threshold, $\theta_{c} \simeq$ $42^{\circ}$. Considering curvilinear depth contours and using a linearly decaying perturbation in bed level we find that $\theta_{c}$ can vary over the range $0-90^{\circ}$ depending on the background bathymetric profile and the depth of closure, $D_{c}$. Associated to the perturbed wave refraction there are two sources of instability: the alongshore gradients in wave angle, wave-angle mechanism, and the alongshore gradients in wave energy induced by wave crest stretching, wave-energy mechanism. The latter are usually de-stabilizing but the former are de-stabilizing only for large enough $D_{c}$, steep foreshores and gently sloping shorefaces. The critical angle comes out from the competition between both mechanisms, but when both are de-stabilizing, $\theta_{c}=0$. In contrast with earlier studies, the model predicts instability for the Holmslands Tange coast so that the observed sand waves could have emerged from such instability. The key point is considering a larger $D_{c}$ that is reasonably supported by both observations and wave climate, which brings the wave-angle mechanism near the de-stabilizing threshold. 


\section{Keypoints:}

- The km-scale shoreline sand waves along the Danish coast could be driven by morphodynamic feedbacks even if wave angles are relatively low

- The instability is caused by alongshore gradients in wave angle and wave energy coupled to the emergent morphology

- Instability for low angles below $42^{\circ}$ are favored by steep foreshores, gen-

tly sloping shorefaces and large depths of closure
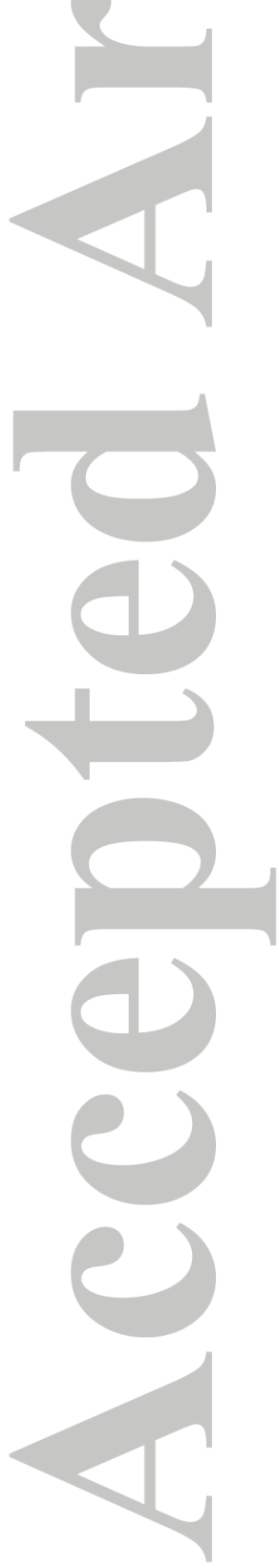


\section{Introduction}

Sandy shorelines may sometimes exhibit an undulating shape in plan view at different

length scales. Beach cusps [Short, 1999] have alongshore wavelength, L, ranging from $\mathrm{O}(1 \mathrm{~m})$ to $\mathrm{O}(10 \mathrm{~m})$. With $L$ ranging from $\mathrm{O}\left(10^{2} \mathrm{~m}\right)$ to $\mathrm{O}\left(10^{3} \mathrm{~m}\right)$ there is a second type, linked to surf zone rhythmic bars and rip channels, known as megacusps [Short, 1999]. Here, we are concerned with a third type of undulations that occur at larger scales, with $L$ roughly in the range $1-10 \mathrm{~km}$. They are typically linked to similar undulations in the bathymetric contours extending offshore beyond the surf zone. These large scale shoreline undulations may be forced by inlets, by islands, by offshore bathymetric anomalies, etc. [Bender and Dean, 2004; McNinch, 2004; Valvo et al., 2006; Ortega-Sánchez et al., 2014].

However, we here deal with those that are not forced externally but that are instead generated by positive feedbacks between waves and morphology through sediment transport.

We refer to them as km-scale shoreline sand waves or simply shoreline sand waves [Idier and Falqués, 2014].

Due to the disparity in length scales, such sand waves are supposed to be not directly related to rhythmic surf zone bars and rip channels. Instead, it has been hypothesized that they may be caused by an instability of the littoral drift (wave-driven longshore transport) coupled to shoreline shape in the case of very oblique wave incidence (we will thereafter refer to this instability as HAWI, i.e., high-angle waves instability) [Ashton et al., 2001]. It was shown in the latter paper that HAWI develops only if the angle of wave incidence with respect to shore normal at the wave base is larger than a critical value, $\theta_{c}$, which is about $\theta_{c} \simeq 42^{\circ}$. Subsequent studies [van den Berg et al., 2012] refined this condition 
by proving that the angle $\theta_{c}$ should not be the offshore value but rather the value at the maximum depth where bathymetric changes associated to shoreline undulations occur. We will hereinafter refer to it as depth of closure, $D_{c}$. More recently, it has been found that even in the case of low angle waves $\left(\theta<42^{\circ}\right)$ the shoreline may also be unstable and give rise to the formation of undulations in case of steep beaches and relatively small wave heights (LAWI, low-angle waves instability, [Idier et al., 2011]). In this case, the undulations tend to be smaller in wavelength and to grow faster.

In recent years, there has been a number of attempts to test HAWI theory against field data [Ashton and Murray, 2006a; Falqués, 2006; Medellín et al., 2009; Kaergaard and Fredsoe, 2013a; Ribas et al., 2013; Idier and Falqués, 2014]. In particular, Kaergaard and Fredsoe [2013a] made a stability analysis for the Holmslands Tange coast (west Danish coast), where shoreline sand waves are observed [Kaergaard et al., 2012], but they could not find shoreline instability. This was attributed to the wave angle being nearly at the threshold of about $42^{\circ}$. In the present contribution we perform again a linear stability analysis for this coast. Our contribution extends the work of Kaergaard and Fredsoe [2013a] by re-examining their $D_{c}$ value and considering observed variable wave parameters in addition to constant mean wave parameters. It is shown that, considering a plausible larger $D_{c}$ value, the Holmslands Tange coast turns out to be unstable and the modeled sand wave characteristics are roughly consistent with observations. Since sand waves can grow with a mean wave angle close to about $42^{\circ}$, the question arises of the origin of the instability. This motivates the main aim of the present study: understanding the physical mechanisms behind shoreline sand wave formation under intermediate wave incidence angles and the relative contributions of HAWI and LAWI instabilities. In section 
2 we briefly describe the sand waves observed on the Holmslands Tange coast and the corresponding linear stability analysis. The onset of HAWI or LAWI and the conditions for each case are discussed in section 3. Section 4 analyzes the interplay of the different processes giving rise to either HAWI or LAWI. We end up with some discussion and the overall conclusions in sections 5 and 6.

\section{Sand waves and shoreline instability}

\subsection{Field observations at Holmslands Tange}

Srd. Holmslands Tange is a sandy beach located at the west Danish coast where shoreline sand waves occur. Figure 1 shows an image of this coast where the corresponding shoreline undulations are visible. Kaergaard et al. [2012] described field measurements of such sand waves reporting a wavelength $L \simeq 5-6 \mathrm{~km}$ and an amplitude (cross-shore distance between the tip of a shoreline cusp and an adjacent embayment) $A \simeq 100 \mathrm{~m}$. In that paper, the averaged migration rate of one of the crests was established to be of $0.37 \mathrm{~km} / \mathrm{yr}$ to the south. However, a closer inspection of their observations (Figure 9 of that paper) shows that the migration rate is not constant: the first 500 days this crest migrates at $0.8 \mathrm{~km} / \mathrm{yr}$ whereas the subsequent 500 days it is stationary. By measuring the migration rate of the whole system (taking into account the two visible crests) we have inferred a mean value $V \simeq 0.46 \mathrm{~km} / \mathrm{yr}$ with a standard deviation of $0.29 \mathrm{~km} / \mathrm{yr}$. There are three breaker bars with a slight obliquity with respect to the coast. The bars migrate to the south but the correlation with the shoreline undulations is very weak. If a sort of mean bathymetry where the bars are filtered out is constructed (volume method, see Kaergaard et al. [2012]), the mean bathymetric contours feature undulations that are

linked to the shoreline undulations and reach at least the $D=5 \mathrm{~m}$ depth contour. In 
fact, looking at Figure 12 of that paper, it is seen that the horizontal amplitude of the undulations in the contours increases seaward and is maximum for the $D=5 \mathrm{~m}$ contour. This indicates that the closure depth, $D_{c}$, would be significantly larger than $5 \mathrm{~m}$. In fact, observed cross-shore bathymetric profiles for Holmslands Tange suggest that $D_{c}>7.7$ $\mathrm{m}$ and we will assume that $D_{c} \simeq 9-13 \mathrm{~m}$ is a reasonable range (see section 5.2 ). The median grain size is about $0.2 \mathrm{~mm}$.

As pertinent wave parameters for this study we use measured waves at station 2031, which is at a distance of $70 \mathrm{~km}$ north of Holmslands Tange at $17.5 \mathrm{~m}$ depth. Data from the 5-year period 2010-14 are considered, which we think are adequate as representative of the average conditions on that coast. In addition of feeding the model with the time series of wave parameters, we also use averages with a certain weighting that is representative of how wave height influences sediment transport. Thus, following Kaergaard and Fredsoe [2013a]:

$$
H_{s m}=<\left(H_{s}\right)^{n}>^{1 / n} \quad, \quad T_{p m}=\frac{<H_{s}^{n} T_{p}>}{<H_{s}^{n}>}
$$

and, for the wave angle:

$$
w_{x}=<H_{s}^{n} \cos (90-|\theta|)>, w_{y}=<H_{s}^{n} \sin (90-|\theta|)>, \quad \theta_{m}=90-\tan ^{-1}\left(w_{y} / w_{x}\right)
$$

where $n$ is the weighting exponent and $<\cdot>$ stands for the time average. Notice that $w_{x}, w_{y}$ represent the $x$ and $y$ components of weighted wave propagation vector and that the sign of the angle is filtered out. An exponent $n=5 / 2$ seems appropriate on account of the equation for the total sediment transport rate (see next section), and we find $H_{s m}=1.7 \mathrm{~m}$, $T_{p m}=7.1 \mathrm{~s}$ and $\theta_{m}=30^{\circ}$. Kaergaard and Fredsoe $[2013 \mathrm{a}]$ used data from wave buoy 2041 (located almost in front of Holmslands Tange at $D=25 \mathrm{~m}$ ), chose the exponent $n=3$ 
for the weighting, and came up with $H_{s m}=1.8 \mathrm{~m}, T_{p m}=6.1 \mathrm{~s}$ and $\theta_{m}=42^{\circ}$. Data from buoy 2041 were not available to us and we use wave buoy 2031 instead for some of our simulations. Notice that the wave angles in the latter buoy are smaller. In order to account for the uncertainty associated to wave data, we consider the range $H_{s}=1.6-2$ $\mathrm{m}$ and $T_{p}=5-7 \mathrm{~s}$. Regarding the angle, we explore the whole range $\theta=0-90^{\circ}$.

We must here remark that the use of mean wave conditions in a stability model must be tackled with care in case of a wave climate characterized by wave directions from both sides of the shore normal, as it is the case at Holmslands Tange. In such case, the resulting mean wave angle (without filtering out the sign) can be small even if most of the waves are high-angle, indicating stability. On the other hand, using an average of the absolute value of the angle as we do (Equation 2, and was also done by Kaergaard and Fredsoe [2013a]), is more appropriate for growth rate computation, but can dramatically overpredict the alongshore celerity of the emerging features. Thus, although mean wave conditions are here also used for comparison and interpretation, we think the outputs of the model that should be compared with nature are those for the observed time series of wave parameters.

\subsection{Linear stability analysis}

To investigate whether shoreline sand waves can emerge from a morphodynamic instability, a linear stability analysis (LSA) is done with the 1D-morfo model described in Falqués and Calvete [2005]. The main concepts of the model are as follows. A small undulation is imposed on an initially rectilinear shoreline, being defined as

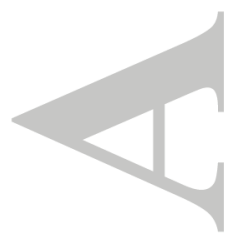

$$
y_{s}(x, t)=\frac{A}{2} e^{\sigma t+i K x}+c . c .
$$


with $x, y$ being Cartesian coordinates in the alongshore and cross-shore directions (respectively), $t$ the time, $K$ the alongshore wavenumber $(L=2 \pi / K)$ and $\sigma=\sigma_{r}+i \sigma_{i}$ the complex growth rate. Here, c.c. means complex conjugate. Regarding the unperturbed state, the main inputs of the model are the cross-shore beach profile and the significant wave height, peak period and angle at a certain depth: $H, T, \theta$ (hereinafter we skip the subindexes "s, p" for the sake of notation simplicity). Regarding the perturbation, the

main inputs are its alongshore wavelength, $L$, its cross-shore shape and the depth of its offshore reach, $D_{c}$. The model provides $\sigma$, from which the characteristic growth time $\sigma_{r}^{-1}$ and the migration celerity $V=-\sigma_{i} / K$ are computed.

For the unperturbed bathymetric profile we use either the observed one at Holmslands Tange (see details in section 2.3) or a shifted Dean-type profile

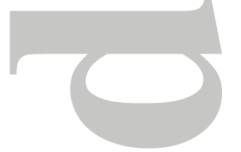

$$
D_{0}(y)=B\left(\left(y+y_{0}\right)^{2 / 3}-y_{0}^{2 / 3}\right)
$$

that can be characterized by the parameter $B$, controlling the overall slope of the shoreface, and the slope at the shoreline, $\beta_{s}$. From these two parameters the shift parameter is obtained as $y_{0}=\left(2 B / 3 \beta_{s}\right)^{3}$. The perturbed bathymetry is characterized by a shape function, $f(y)$, as

$$
D(x, y, t)=D_{0}(y)-\beta_{s} f(y) y_{s}(x, t)
$$

where $D(x, y, t)$ is the mean water depth. A linearly decaying bed level perturbation is here considered, $f(y)=1-y / y_{c}$, for $0 \leq y \leq y_{c}$ and $f(y)=0$ for $y>y_{c}$, where $D_{0}\left(y_{c}\right)=D_{c}$

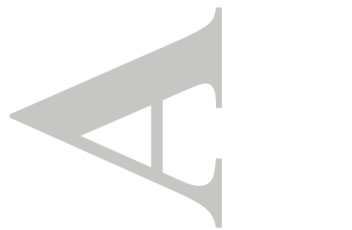

(C)2017 American Geophysical Union. All Rights Reserved. 
To compute the growth rate, equation (3) is inserted into the one-line sediment conservation equation [Komar, 1998]

$$
\frac{\partial y_{s}}{\partial t}=-\frac{1}{\bar{D}} \frac{\partial Q}{\partial x}
$$

where $\bar{D}$ is a mean depth of the morphodynamic active zone and $Q$ is the total alongshore sediment transport rate. Here, $Q$ is computed with the CERC formula [Komar, 1998]

$$
Q=\mu H_{b}^{5 / 2} \sin \left(2 \alpha_{b}\right)
$$

where $H_{b}, \alpha_{b}$ are the wave height and wave angle with respect to the local shore normal at breaking and $\mu$ is an empirical constant. In the present contribution it is set to $\mu=0.15$ $\mathrm{m}^{1 / 2} \mathrm{~s}^{-1}$ (more information is given in section 5.3).

Computing the left hand side of equation (6) is straightforward from equation (3) but computing the right hand side requires calculating the perturbed $H_{b}$ and $\alpha_{b}$. This is done by linearizing (with respect to $A$ ) the equations describing refraction and shoaling over the perturbed bathymetry and computing $H_{b}$ and $\alpha_{b}$ numerically [Falqués and Calvete, 2005]. Another important output of the model, which will be here crucial, is the alongshore distribution of the perturbed $Q, H_{b}$ and $\alpha_{b}$.

By default, the model assumes wave parameters $H, T, \theta$ that are constant in time during a time interval $0 \leq t \leq t_{F}$ and provides the complex amplification factor, $\exp \left(\sigma t_{F}\right)$, for each alongshore wavelength $L$ during this interval. For a time series of wave parameters defined by $\left\{H_{j}, T_{j}, \theta_{j} ; j=1,2, \ldots N\right\}$ for the time intervals $\{(j-1) \Delta t \leq t<$ $j \Delta t ; j=1,2, \ldots N\}$ the amplification factor for wavelength $L$ and for each time interval is $\exp \left(\sigma_{j} \Delta t\right)$. Since the solution of the linearized governing equations is exponential in 
time, the resulting amplification factor for the whole time period, $0 \leq t \leq t_{F}$, is

$$
e^{\sigma_{1} \Delta t} e^{\sigma_{2} \Delta t} \ldots e^{\sigma_{N} \Delta t}=e^{\sigma t_{F}}
$$

where $t_{F}=N \Delta t$ and where $\sigma$ is the resulting complex growth rate for wavelength $L$.

\subsection{Stability analysis for Holmslands Tange}

To apply the stability model to Holmslands Tange, the observed mean unperturbed beach cross-shore profile shown in Figure 2 is used. Regarding the closure depth, we explore the range $D_{c}=7-15 \mathrm{~m}$, which includes $D_{c}=9-13 \mathrm{~m}$ (the range assumed to be representative of Holmslands Tange). For the wave conditions, and according to section 2.1, we first consider the time series of measured waves at station 2031 during 2010-14. Figure 3 displays the wave height and wave angle, showing two extreme storms with $H \approx 12-13 \mathrm{~m}$ and other severe storms with $H \approx 7-8 \mathrm{~m}$. It also becomes apparent that negative angles with respect to shore normal, i.e., waves from the NW, are the most frequent. Figure 3 also shows the time series of real growth rates, $\left(\sigma_{r}\right)_{j}$, corresponding to the time intervals, $(j-1) \Delta t \leq t<j \Delta t$, associated to each wave record $\left(H_{j}, T_{j}, \theta_{j}\right)$ for a $L=6 \mathrm{~km}$ wavelength and for two cases: $D_{c}=7 \mathrm{~m}$ and $D_{c}=11 \mathrm{~m}$. It is seen that positive growth rates dominate for $D_{c}=11 \mathrm{~m}$ while negative values dominate for $D_{c}=7$

m. As a result and as it is shown in Figure 4, the resulting real growth rate is positive for the $D_{c}=11 \mathrm{~m}$ indicating instability, while $D_{c}=7 \mathrm{~m}$ is in the stable region. During the extreme storms the growth rates are negative in both cases with a large magnitude. This means that big storms tend to damp the sand waves. The maximum decay rate occurs for the biggest storm and for $D_{c}=7 \mathrm{~m}$, on $17 / 10 / 2012$, with a characteristic decay time of about 1.4 days. This is extremely fast in comparison with the maximum growth time 
of about 90 days, obtained for $D_{c}=11 \mathrm{~m}$. Thus, it seems that sand waves at Holmslands Tange slowly grow during the long time periods with fair weather or moderate storms whereas they are quickly damped during severe storms. Notice that actual wave angles in front of Holmslands Tange are larger than those measured at buoy 2031 (see section 2.1), so that growth rates are probably underestimated in the computations based on this buoy.

Figure 4 shows the dominant wavelength (linearly most amplified wavelength), $L$, the corresponding alongshore celerity, $V$, and the associated (resulting) characteristic growth time, $\sigma_{r}^{-1}$, as a function of $D_{c}$. It is found that sand waves do not grow for $D_{c}<9.2 \mathrm{~m}$.

For $D_{c}=11-15 \mathrm{~m}$ the predicted wavelength is $L \simeq 6 \mathrm{~km}$, in very good agreement with the observed one, while for $D_{c}<11 \mathrm{~m}$ it is slightly overpredicted. The predicted celerity is $V \simeq 0.2 \mathrm{~km} / \mathrm{yr}$, which is consistent with the observed one within its large uncertainty. The characteristic growth times are in the order 5-15 yr. We have also examined constant mean wave conditions, in which case we have chosen weighted averaged conditions for station 2041 because they are more representative of the site. According to section 2.1 the default values are $H=1.8 \mathrm{~m}, T=6.1 \mathrm{~s}$ and $\theta=42^{\circ}$ and we explore the sensitivity in the range $H=1.6-2 \mathrm{~m}, T=5-7 \mathrm{~s}$ and $\theta=0-90^{\circ}$. Our analysis confirms the results of Kaergaard and Fredsoe [2013a] according to which there is no instability for $D_{c}=5 \mathrm{~m}$ (Figure 4). By increasing $D_{c}$ the instability first occurs in this case for $D_{c} \simeq 7.4 \mathrm{~m}$ and for the range $D_{c}=9-13 \mathrm{~m}$ we obtain $\sigma_{r}^{-1}=2.8-3.3 \mathrm{yr}, L \simeq 4.5-5.5$ $\mathrm{km}$ and $V=0.6-0.8 \mathrm{~km} / \mathrm{yr}$. Looking at the sensitivity with respect to $H$ and $T$, the most robust model output is the wavelength, ranging within $L=4.2-5.9 \mathrm{~km}$. The celerity and the growth rate have a higher variability within the range $V=0.35-1.1$ 
$\mathrm{km} / \mathrm{yr}$ and $\sigma_{r}^{-1}=1.8-6 \mathrm{yr}$, respectively. Furthermore, comparing the model runs for the time series of wave parameters with the runs for mean wave conditions, it turns out that the differences are relatively small for the wavelength while they are quite large for the growth time. The wavelengths and the growth times tend to be smaller for mean wave conditions. The differences are more dramatic for the celerity, which is significantly larger for mean wave conditions. This is due to the fact that the mean angle, $\theta \sim 42^{\circ}$, was computed with the absolute values of the measured angles with respect of the shore normal (see the comment at the end of section 2.1).

It is interesting to examine how the sand wave characteristics depend on the wave angle for different $D_{c}$ values, in case of constant wave conditions. Figure 5 shows how two significantly different behaviors occur depending on $D_{c}$. For $D_{c} \geq 12 \mathrm{~m}$ there is instability for any angle, as can be seen for $D_{c}=13 \mathrm{~m}$. In contrast, for $D_{c}<12 \mathrm{~m}$ there is no instability below a certain threshold angle, $\theta_{c}$. For instance, as is shown in Figure $5 \mathrm{~b}, \theta_{c}=18^{\circ}$ for $D_{c}=10 \mathrm{~m}$ and $\theta_{c}=45^{\circ}$ for $D_{c}=7 \mathrm{~m}$. For $D_{c}=9 \mathrm{~m}$, which is the lower bound of the closure depth range we have assumed for Holmslands Tange, there is a critical angle of $\theta_{c}=26^{\circ}$. This means that if $D_{c} \geq 9 \mathrm{~m}$ and $\theta \geq 26^{\circ}$ sand waves can emerge from shoreline instability at Holmslands Tange. Figure 5 also shows that small changes in the angle around $42^{\circ}, \Delta \theta= \pm 10^{\circ}$, do not change significantly the ranges of the values of $L, V$ and $\sigma_{r}^{-1}$.

\section{HAWI vs LAWI regimes}

The reasonable agreement between model results and observations along with the fact that the wave angle at Holmslands Tange is nearly at the threshold for HAWI according to Ashton et al. [2001] deserves further attention. In fact, Figure 5b shows how for 
$D_{c} \geq 9 \mathrm{~m}$ the instability survives well below $\theta=42^{\circ}$. This suggests that the sand waves at Holmslands Tange could be triggered by LAWI rather than HAWI and motivates investigating the reasons for it. In particular, we want to find out the general characteristics of the bathymetric profile and of $D_{c}$ that favor either HAWI or LAWI and whether the conditions at Holmslands Tange are well within the LAWI region or near the transition. Thus, we do a general exploration with a shifted Dean-type bathymetric profile . According to Kaergaard and Fredsoe [2013a], $B=0.09 \mathrm{~m}^{1 / 3}$ can be considered as representative of Holmslands Tange (the small shift $y_{0}$ only affects the bathymetry very close to shore, overall the profile behaves as a Dean one, $\left.D_{0}(y) \simeq B y^{2 / 3}\right)$. The shoreline slope can be approximated by $\beta_{s}=0.023$, which is the mean slope of the surf zone for the mean observed profile [Kaergaard, 2011]. As default wave conditions we use the mean (weighted) conditions observed on that coast, $H=1.8 \mathrm{~m}, T=6.1 \mathrm{~s}$ at $D=25 \mathrm{~m}$, according to section 2.1.

In the context of the LSA, and for a background beach profile, a wave height and a wave period, we refer to the beach conditions as being in the LAWI regime if there are growing sand waves for any wave incidence angle. In contrast, if there is a critical wave angle, $\theta_{c}$, such that for $\theta<\theta_{c}$ any sand wave decays whereas for $\theta>\theta_{c}$ there exist growing sand waves, we refer to the HAWI regime. Finally, if there is no growing sand waves for any wavelength and any angle, such beach conditions are considered to be in the stable regime.

We find that instability needs in any case a minimum $D_{c}$ and that just above this critical value it always starts in the HAWI regime. By further increasing $D_{c}$ the system switches from the HAWI to the LAWI regime (see, e.g., Figures 4 and 5). In addition to a large 
$D_{c}$ the LAWI regime is favored by a large shoreline slope, $\beta_{s}$, combined with a small $B$ (i.e., a gently sloping shoreface), hence a concave profile. This can be seen in Figure 6a, which shows the transition between the HAWI/LAWI regimes as a function of the depth of closure, $D_{c}$, and the bathymetric parameters $\beta_{s}$ and $B$. The transition beach profiles for $\beta_{s}=0.023$ and $D_{c}=5,13,20 \mathrm{~m}$ are plotted in Figure $6 \mathrm{~b}$. The profile for $D_{c}=13 \mathrm{~m}$ corresponds approximately to that of Holmslands Tange, meaning that Holmslands Tange would be in the LAWI regime if $D_{c}>13 \mathrm{~m}$ and in the HAWI regime if $D_{c}<13 \mathrm{~m}$. Notice that the transition at $D_{c}=13 \mathrm{~m}$ is for the shifted-Dean type profile (dashed line in Figure 2). For the observed profile (solid line in Figure 2) the transition occurs at $D_{c}=12 \mathrm{~m}$.

The critical angle, $\theta_{c}$, for instability without caring whether it is HAWI or LAWI is presented in Figure 7 as a function of $B$ and $D_{c}$ for $\beta_{s}=0.023$. The results are fully consistent with the discussion presented above. The critical angle decreases for decreasing $B$ and increasing $D_{c}$ and at some point it becomes $\theta_{c}=0$, that is, the LAWI regime starts. For instance, from $B=0.1 \mathrm{~m}^{1 / 3}$ this happens for $D_{c}=20 \mathrm{~m}$ but for $B=0.05 \mathrm{~m}^{1 / 3}$ it happens for $D_{c}=7 \mathrm{~m}$.

\section{Physics behind HAWI/LAWI interplay}

\subsection{Alongshore position of the maximum in sediment transport rate and instability}

The growth/decay of a shoreline sand wave in the one-line approximation is linked to the alongshore position of the maximum in sediment transport rate, $Q$. Indeed, given a small amplitude shoreline undulation defined by equation (3), the wave height at breaking $H_{b}$ and the relative wave angle $\alpha_{b}$ vary sinusoidally alongshore (to first order in $A$ ) and

$Q$ does so according to equation (7). Its corresponding linearized version reads

(C)2017 American Geophysical Union. All Rights Reserved. 


$$
Q=Q_{0}+A q e^{\sigma t+i(K x-\Psi)}+\text { c.c. }
$$

where $Q_{0}$ is the alongshore uniform flux for the unperturbed shoreline, $A$ is the amplitude of the shoreline undulation (equation 3), $A q$ is the real amplitude of the perturbation in the sediment flux and $\Psi$ is its phase with respect to the sand wave (notice that the actual computation of $q$ and $\Psi$ requires solving numerically the linearized equations of wave propagation over the perturbed bathymetry [Falqués and Calvete, 2005]). For example, $\Psi=\pi / 2$ means that the maximum in $Q$ is $L / 4$ downdrift of the crest, at the inflection point. Inserting equations (3) and (9) into equation (6) provides the real and imaginary growth rates

$$
\sigma_{r}=-\frac{2 q K}{\bar{D}} \sin \Psi \quad, \quad \sigma_{i}=-\frac{2 q K}{\bar{D}} \cos \Psi
$$

from where it is easily seen that the sand wave grows if and only if $-\pi<\Psi<0$, that is, if the maximum in sediment transport is located between the crest and the updrift embayment (also illustrated in Figure 8). Similarly, the sand wave propagates downdrift if and only if $-\pi / 2<\Psi<\pi / 2$, that is, if the maximum in $\mathrm{Q}$ is between the two inflection points updrift and downdrift the crest.

The position of the maximum in $Q$ depends in turn on the positions of the maxima in the perturbed $H_{b}$ and $\alpha_{b}$ and on the amplitude of such perturbations. This can be worked out by assuming similar expressions

$$
H_{b}=H_{b 0}+A H_{b 1} e^{\sigma t+i\left(K x-\Psi_{H}\right)}+c . c . \quad, \quad \alpha_{b}=\alpha_{b 0}+A \alpha_{b 1} e^{\sigma t+i\left(K x-\Psi_{\alpha}\right)}+\text { c.c. }
$$

where $H_{b 0}, \alpha_{b 0}$ are the unperturbed values of $H_{b}$ and $\alpha_{b}, A H_{b 1}, A \alpha_{b 1}$ are the intensities of their perturbations and $\Psi_{H}, \Psi_{\alpha}$ give the positions of their maxima. By inserting these expressions into equation (7) and linearizing with respect to $A$, the following expression (C)2017 American Geophysical Union. All Rights Reserved. 
is found,

$$
\tan \Psi=r \tan \Psi_{H}+(1-r) \tan \Psi_{\alpha}
$$

which gives the position of the maximum in $Q$ with respect to the sand wave crest, where

$$
r^{-1}=1+\frac{4}{5} \frac{H_{b 0}}{\tan \left(2 \alpha_{b 0}\right)} \frac{\alpha_{b 1}}{H_{b 1}} \sqrt{\frac{1+\left(\tan \Psi_{H}\right)^{2}}{1+\left(\tan \Psi_{\alpha}\right)^{2}}}
$$

measures the relative influence of $H_{b}$ and $\alpha_{b}$. Because of the alongshore periodicity we can focus only on one wavelength between $x=-L / 2$ and $x=L / 2$ of a sand wave with the crest at $x=0$. We define $x_{Q}, x_{H}$ and $x_{\alpha}$ as the alongshore positions of the maxima in $Q, H_{b}$ and $\alpha_{b}$, respectively. From equation (13) it is readily seen that if $H_{b 1} / H_{b 0} \gg \alpha_{b 1} / \tan \left(2 \alpha_{b 0}\right)$, $r \simeq 1$ so that $\Psi \simeq \Psi_{H}$ and $x_{Q} \simeq x_{H}$, that is, the location of the $Q$ maximum is dominated by the location of the $H_{b}$ maximum. In case $H_{b 1} / H_{b 0} \ll \alpha_{b 1} / \tan \left(2 \alpha_{b 0}\right), r \simeq 0$ and the location of the $Q$ maximum is dominated by the location of the $\alpha_{b}$ maximum. In general, if both quantities are comparable, $x_{Q}$ is in between $x_{H}$ and $x_{\alpha}$.

\subsection{Wave-energy and wave-angle instability mechanisms}

For oblique wave incidence, if both $x_{H}$ and $x_{\alpha}$ are at the downdrift flank of the sand wave, $0<x<L / 2, x_{Q}$ is also there and the sand wave decays. Therefore, the growth requires that at least one out of $x_{H}$ and $x_{\alpha}$ is at the updrift flank. Due to less refractive wave front stretching, wave height tends to be larger at the updrift flank (Figure 9a). This tends to bring $x_{H}$ there and has been recognized as the essential process driving HAWI [Ashton and Murray, 2006b; Falqués et al., 2011; van den Berg et al., 2012, 2014].

On the other hand, since the angle between the local shoreline and the unperturbed shoreline is at first order given by $\partial y_{s} / \partial x=-A K \sin (K x)$, the relative wave angle can be

cast into $\alpha_{b}=\theta_{b}+A K \sin (K x)$, where $\theta_{b}$ is the absolute wave angle at breaking, i.e., the (C)2017 American Geophysical Union. All Rights Reserved. 
wave incidence angle with respect to the $y$ axis at breaking. Then, if the perturbation in $\theta_{b}$ is small, the relative angle has its maximum near the maximum in $A K \sin (K x), x_{\alpha} \simeq L / 4$. This is the well-known situation in a HAWI unstable shoreline, where the alongshore gradients in $H_{b}$ tend to destabilize whereas the gradients in $\alpha_{b}$ tend to stabilize and the critical angle of about $\theta_{c} \simeq 42^{\circ}$ comes out of that competition, $H_{b}$ dominating for large angle and $\alpha_{b}$ dominating for low angle.

On the other hand, due to less wave refraction at the updrift flank, $\theta_{b}$ tends to be maximized there and if its magnitude is large enough, this can overcome the effect of the shoreline angle $(A K \sin (K x))$ and bring $x_{\alpha}$ updrift of the crest (Figure 9b). In this situation, the alongshore gradient in relative angle tends to cause growth of the sand wave too and there is no critical angle for the onset of instability because both mechanisms work in the same direction. This is the essential process driving LAWI [Idier et al., 2011].

Hereinafter we will refer to wave-energy instability (wave-angle instability) as the shoreline instability caused by the alongshore gradients in wave energy (wave angle) that is associated to the maximum in energy (maximum in relative angle) being located at the updrift flank.

\subsection{Identifying the different scenarios}

In principle, HAWI is caused by the wave-energy instability mechanism whereas LAWI is caused by the wave-angle instability mechanism. However, a more complex picture becomes apparent by examining the positions of $x_{H}, x_{\alpha}$ and $x_{Q}$ as a function of $\theta$. Figure 10 shows examples of such curves for $L=5800 \mathrm{~m}$, a particular wavelength in the range observed at Holmslands Tange, for $H=1.8 \mathrm{~m}$ with different values of $\beta_{s}, B$ and $D_{c}$

$(T=5.1 \mathrm{~s}$ and $6.1 \mathrm{~s})$. The values are chosen to show clear illustrative examples. Generally, 
the wave energy gradients de-stabilize $\left(-L / 4<x_{H}<0\right)$ for all angles, as it is seen in panels a) to d). However, for concave profiles with large closure depths, they can stabilize $\left(0<x_{H}<L / 4\right.$, panel e). The gradients in wave angle can de-stabilize $\left(-L / 4<x_{\alpha}<0\right)$ for any angle (panels $\mathrm{d}$ and e) or they can stabilize $\left(0<x_{\alpha}<L / 4\right)$ for any angle (panels a and b), the typical situation in earlier studies (e.g., Falqués and Calvete [2005]) where LAWI was not found. However, they also can stabilize for low angles and destabilize for high angles (panel c). The overall stability/instability of this particular wavelength, resulting from the interplay of both gradients, is given by the position of $x_{Q}$ and corresponds to the LAWI regime for panels d) and e), to the HAWI regime for panels b) and c) and to the stable regime for panel a).

From the positions of $x_{H}, x_{\alpha}$ and $x_{Q}$ for different wavelengths, the transition curves in $L-\theta$ diagrams for the wave-energy instability, the wave-angle instability and the resulting overall instability can be drawn for the various sets of parameter values. Then, three types of behavior are identified as a function of the beach profile and $D_{c}$ : LAWI, pure-HAWI and mixed-HAWI. This is illustrated in Figure 11 for the profile representing Holmslands Tange, $\beta_{s}=0.023, B=0.09 \mathrm{~m}^{1 / 3}$, and for $D_{c}=7,13$ and $20 \mathrm{~m}$.

A LAWI regime, i.e., a situation where there is instability for any angle, is shown in Figure 11c for $D_{c}=20 \mathrm{~m}$. For small $L$, both wave energy and wave angle gradients stabilize. Above some critical wavelength depending on $\theta$, wave-angle gradients destabilize while wave-energy gradients stabilize. By increasing $L$ above that critical value, the former gradients become dominant and the onset of instability is reached (also illustrated in Figure 10e). By further increasing $L$ both mechanisms contribute to instability (also illustrated in Figure 10d). 
A HAWI regime, i.e., a scenario where sand waves grow only above a critical angle and for large enough wavelength, is shown in Figure 11 a for $D_{c}=7 \mathrm{~m}$ (here, $\left.\theta_{c} \simeq 48^{\circ}\right)$. The instability source is the wave-energy mechanism, the wave angle gradients stabilizing. This is also illustrated in Figure 10a and 10b for the unstable and stable situations, respectively. We can refer to this type as pure-HAWI.

Figure 11b illustrates a HAWI regime with a more complex behavior, for $D_{c}=13 \mathrm{~m}$. Below $\theta \simeq 38^{\circ}$ wave energy gradients destabilize while wave angle gradients stabilize, i.e., the typical HAWI situation. There is a critical angle for instability, $\theta_{c} \simeq 10^{\circ}$, given by the competition of these two mechanisms that is significantly lower than that of Ashton et al. [2001]. However, by further increasing the angle, for $\theta>38^{\circ}$, the role of the gradients in wave energy and in wave angle switches and the behavior becomes that described in Figure 11c, which is typical for LAWI. Therefore, although this situation can be characterized as HAWI regime in the sense that there exists $\theta_{c}$, regarding the physical instability mechanisms it is HAWI-like for moderate angles and LAWI-like for large angles. This behavior becomes also apparent in Figure 10c, which is in fact similar to Figure 10b but the wave-angle gradients are now destabilizing for large angles too. The typical scenario of HAWI occurs only for a range of angles (here, $10^{\circ}<\theta<38^{\circ}$ ) whereas for larger angles the instability is due to both mechanisms, wave-energy and wave-angle. We can refer to this situation as mixed-HAWI.

\section{Discussion}

\subsection{Instability mechanisms}

Our general exploration by varying the cross-shore beach profile, the depth of closure and the wave angle suggests abandoning the HAWI/LAWI distinction and referring prefer- 
ably to 'km-scale littoral drift induced instability'. In contrast with Ashton et al. [2001], our study reveals that the critical angle for the onset of the instability can vary over the whole range $0-90^{\circ}$, depending on the profile of the shoreface and the depth of closure (it could depend on wave height and period but this has not been investigated here). This is found to be the result of the competition between the wave-energy and wave-angle instability mechanisms. The reason why Ashton et al. [2001] obtained a strict threshold for instability is that in their model the depth contours are approximated by straight and parallel lines and refraction is done with the Snell law. In this case, the wave-angle instability effect can only weaken the stabilizing effect of the changes in shoreline orientation but it can never overcome it because the wave fronts can never change the sign of their angle with respect to the bathymetric contours. Then, there is only a competition between that stabilizing effect and the wave-energy instability mechanism [Falqués et al., 2011] with a transition for $\theta_{c} \simeq 42^{\circ}$. Only when the wave-angle instability mechanism plays a role, shoreline instability can occur for relatively low angles. According to our model computations, the wave-angle instability mechanism (and therefore a low $\theta_{c}$ ) is enhanced by a large depth of closure, $D_{c}$, and a gently sloping shoreface (small $B$ ) because this increases the distance travelled by the waves over the sand wave bathymetry before reaching the breaking point. Moreover, for a given horizontal amplitude of the shoreline undulation, a steeper foreshore implies a larger amplitude of the bathymetric perturbation, so that the perturbation in wave refraction is more intense. These trends can be understood from the mathematical analysis that is presented in Appendix A.

It is intriguing that previous modeling studies accounting for the local curvature of the depth contours [Falqués and Calvete, 2005; van den Berg et al., 2012; Kaergaard and 
Fredsoe, 2013a] did not find the LAWI instability, except for Idier et al. [2011]. One possible reason is that either the explored bathymetric profiles were not prone to LAWI or the values used for $D_{c}$ were too small. The default values for those studies were $D_{c}=10,8,4 \mathrm{~m}$ and $B=0.07,0.13,0.1 \mathrm{~m}^{1 / 3}$, respectively. The slope at the shoreline was $\beta_{s}=0.01$ and 0.03 for the two first papers while it was not defined for the third one as they used a standard Dean profile, $D=B y^{2 / 3}$. According to Figure 6 , the set of default values for Falqués and Calvete [2005] and van den Berg et al. [2012] falls into the HAWI regime. Regarding Kaergaard and Fredsoe [2013a] their values cannot be located in that diagram since $\beta_{s}$ is not defined. However, the low $D_{c}$ values along with the relatively large $B$ values would suggest a HAWI regime too. The second possible reason is related with the differences in the cross-shore shape of the bed level perturbation. Kaergaard and Fredsoe [2013a] used a shift of the equilibrium profile whereas Falqués and Calvete [2005] used an exponentially decaying bed level perturbation that also matches a profile shift near the shore. In contrast, Idier et al. [2011] used an exponentially decaying bed level perturbation, exploring large decay distances that approximately lead to a linear decay as in the present study. It is difficult to ascertain which bathymetric perturbation shape is the most realistic. In the long term, it is reasonable to assume that a cross-shore shift of the shoreline position will imply the same shift of the equilibrium profile (the basis for the Bruun rule). However, sand waves are dynamic and by the time the bathymetric perturbation had fully adapted to a shoreline shift, the undulation in the coastline would have migrated alongshore. Furthermore, the adaptation of the shoreface to changes in the coastline is non homogeneous, deeper areas requiring longer time [Ortiz and Ashton, 2016]. Thus, it is also reasonable to assume a linearly (or similar) decaying perturbation 
in bed level as we assume here. Finally, the cross-shore shape of the perturbation could be extracted from observations. For example, in the case of Holmslands Tange, the linearly decaying perturbation adopted in the present contribution is coherent with the shape of the total bathymetry shown in Figure 12 of Kaergaard et al. [2012]. Anyway, further work is needed to investigate the role of the cross-shore bathymetric shape of the sand wave on its dynamics.

\subsection{Depth of closure}

Our analysis has revealed a strong dependence on $D_{c}$. A range $D_{c}=5-15 \mathrm{~m}$ has been examined in section 2.3 and, in particular, $D_{c}=9-13 \mathrm{~m}$ has been assigned to Holmslands Tange. This deserves further discussion, especially because Kaergaard and Fredsoe [2013a] chose $D_{c}=5-7 \mathrm{~m}$. There is some uncertainty on $D_{c}$ [Ortiz and Ashton, 2016] and there are several methods to come up with an input value for the model. First

of all, a direct measurement from bathymetric observations at the sand wave field would be desirable. Although such measurement is not available for Holmslands Tange, the bathymetric observations reported by Kaergaard et al. [2012] suggest that $D_{c}$ would be substantially larger than $5 \mathrm{~m}$ (see Section 2.1). In fact, cross-shore bathymetric profiles in front of Holmslands Tange (K. Kaergaard, personal communication) show that the long term bed level variability is very high at the surf zone and decreases seaward to reach a minimum value of $\Delta z_{b} \approx 0.5 \mathrm{~m}$ at a water depth of $D=7.7 \mathrm{~m}$. Seaward of this point it increases again, possibly related to tidal and current sand waves that have been observed off the Danish west coast at depths ranging from 8 to $18 \mathrm{~m}$ [Anthony and Leth, 2002]. The threshold bed change to define $D_{c}$ is not unique, it is typically defined on the basis of the resolution of bathymetric measurements but is usually smaller than $0.5 \mathrm{~m}$, in the range 
$0.05-0.5 \mathrm{~m}$ [Nicholls et al., 1998]. Thus, since the variability in bed level at $D=7.7$ $\mathrm{m}$ in the bathymetric measurements is above the common threshold, $D_{c}>7.7 \mathrm{~m}$. More importantly, since the mean bed slope at such water depth is about 0.004 (see Figure 2) a depth level variation $\Delta z_{b} \approx 0.5 \mathrm{~m}$ could correspond to a horizontal amplitude of undulations in the depth contours of about $0.5 / 0.004=125 \mathrm{~m}$, i.e, comparable to the shoreline undulations. This would indicate that $D_{c}$ could be substantially larger than $7.7 \mathrm{~m}$. Supporting this claim there are detailed measurements from the northern Dutch coast giving $D_{c}=9 \mathrm{~m}$ at Petten and Terschelling [Hinton and Nicholls, 1998; Marsh et al., 1998]. The threshold for the bed changes in those studies was of $0.5 \mathrm{~m}$ and the time period 20 and $25 \mathrm{yr}$, respectively. Since the wave climates from both coasts are not significantly different, this would provide an indication of $D_{c}$ for the west Danish coast. Finally, regarding observations, the offshore sand waves observed at depths of $8-18 \mathrm{~m}$ [Anthony and Leth, 2002] reveal a significant sediment mobility at $D>8 \mathrm{~m}$ (see also Christensen et al. [2001]). Although they are not related to wind waves nor linked to shoreline undulations, they could increase the effective $D_{c}$ for the shoreline sand waves.

In addition to direct observations, another method is using engineering estimates based on wave climate, for example

$$
D_{c}=2.28 H_{e}-68.5 \frac{H_{e}^{2}}{g T_{e}^{2}}
$$

where $H_{e}$ is the significant wave height exceeded only 12 hours during a reference time and $T_{e}$ is the associated wave period [Hallermeier, 1978]. Previous modeling studies have shown that the relevant time scale of shoreline sand waves is in the range $1-10$ yr [Falqués and Calvete, 2005; van den Berg et al., 2012]. Another estimate of the order of magnitude of this time scale is provided by the observed migration period $T_{m i}=L / V \simeq 5.5 / 0.5 \simeq$ (C)2017 American Geophysical Union. All Rights Reserved. 
11 yr. By choosing 10 yr as reference time, and using data from wave buoy 2031 during the period 2005-2014, we find $H_{e}=6.7 \mathrm{~m}, T_{e}=11.4 \mathrm{~s}$, from where equation (14) gives $D_{c}=13 \mathrm{~m}$. Following the same method and using another similar formula [Birkemeier 1985] the value $D_{c}=10 \mathrm{~m}$ is obtained. Results are very similar if a 5 -yr period is used (2010-2014). The depth of closure can also be inferred from a mechanistic morphodynamic approach. Based on an energetic approximation to the wave-driven cross-shore transport, Ortiz and Ashton [2016] derived an advection-diffusion equation for bed level. They showed that the shoreface is dominated by diffusion and obtained an expression for the morphodynamic diffusivity. From it, the time needed for shoreline perturbations to reach certain offshore distance can be estimated. This provides an estimate of $D_{c}$ as a function of the reference time, wave height and period. We used data from wave buoy 2031 and, since cross-shore transport in their formulation is proportional to $H^{5}$, we computed mean wave height and period by weighting with $H^{5}$ for the $2005-2014$ period. The result is $\bar{H}=2.5 \mathrm{~m}$ and $\bar{T}=9.1 \mathrm{~s}$, from where Figure 6 of Ortiz and Ashton [2016] gives $D_{c} \simeq 14$ $\mathrm{m}$.

Finally and at a global scale, the range of $D_{c}=5-20 \mathrm{~m}$ considered for the investigation of the instability mechanisms is not unrealistic. We have used wave data from the IOWAGA modeling system [Rascle and Ardhuin, 2013], which is based on the wave model WAVEWATCH III (see Tolman et al. [2013] and references herein), for the 2001-2010 period. By applying equation (14) we obtained a range $3-24 \mathrm{~m}$ for $D_{c}$ on the world coastlines (excluding very low energy coasts).

\subsection{Application to Holmslands Tange}


It has been found that the time varying wave parameters together with the averaged cross-shore beach profile of Holmslands Tange might trigger shoreline instability at Srd. Holmslands Tange if $D_{c} \geq 9.2 \mathrm{~m}$. Recall that the growth rates computed with data from station 2031 are probably underestimated so that this threshold might be smaller. Although the exact value of $D_{c}$ is unknown, a reasonable range is $9-13 \mathrm{~m}$ so that the hypothesis that the shoreline sand waves are driven by this instability is very plausible, which is in contrast with the previous study of Kaergaard and Fredsoe [2013a] who considered lower $D_{c}$ values. Another difference with Kaergaard and Fredsoe [2013a] is the shape of the bathymetric perturbation associated to the sand waves: they assumed a shift of the depth contours following the perturbed shoreline whereas we assume a bed level perturbation linearly decaying with distance to shore. The range of the most amplified wavelength is consistent with the wavelength of the observed sand waves in that coast, $L=5-6 \mathrm{~km}$. It is important to account, however, that the present stability model does not resolve surf zone hydrodynamics and disregards wave directional spreading. Uguccioni et al. [2006] showed that the inertia in the longshore current could increase $L$ by $17 \%$. Kaergaard and Fredsoe [2013b] presented computations for a generic case showing an increase in $L$ by a factor 2 due to a large directional spreading. We do not know to which extent the results of Kaergaard and Fredsoe [2013b] apply to Holmslands Tange in a quantitative way and which is the directional spreading attributable to the mean wave conditions in that coast. However, for moderate directional spreading (e.g., DSI > 20 in that paper) the effect should be rather minor (less than a $20 \%$ increase). The observed alongshore celerity has an important uncertainty within the range $V \approx 0.2-0.8 \mathrm{~km} / \mathrm{yr}$. The model computations, $V \approx 0.15-0.2 \mathrm{~km} / \mathrm{yr}$, are at the lower bound of the observed 
range, underpredicting the mean value by a factor 2.5. Here we must recall that the empirical $\mu$ constant in the sediment transport formula (equation 7 ) only affects the time scale of the instability, so that $V$ and $\sigma_{r}$ are proportional to $\mu$. Since $\mu=0.15 \mathrm{~m}^{1 / 2} \mathrm{~s}^{-1}$ has been used here, a better agreement would be obtained by choosing $\mu \approx 0.38 \mathrm{~m}^{1 / 2}$ $\mathrm{s}^{-1}$. For a sediment relative density of 2.65, a breaking index $\gamma=0.6$ and a sand porosity $p=0.4$ this corresponds to a value $K_{\text {cerc }} \approx 0.95$ of the nondimensional constant in front of the CERC formula, which fits into the accepted range, $0.2-1.6$ [Komar, 1998]. There are no available data on the characteristic growth time but the range of the model values, $5-15 \mathrm{yr}$, is within the correct order of magnitude according to existing observations of km-scale shoreline sandwaves (see, e.g., Leont'ev et al. [2011]). This order of magnitude can also be inferred from the observed migration period, $T_{m i} \sim 11 \mathrm{yr}$ (see Section 5.2). Therefore, the sand waves at Holmslands Tange could be originated by a km-scale littoral drift induced instability.

Constant mean wave conditions have also been considered for comparison and interpretation. For the default wave conditions, $H=1.8 \mathrm{~m}, T=6.1 \mathrm{~s}$ and for $9 \leq D_{c}<12$ $\mathrm{m}$, the shoreline would be unstable only above a critical angle, $\theta_{c}$, which is $\theta_{c}<26^{\circ}$ (see Figure 5a). In contrast, for $D_{c} \geq 12 \mathrm{~m}$ the shoreline is unstable for any angle (see Figure 5). Thus, the instability at Holmslands Tange is either of LAWI or mixed-HAWI type (see Section 4.3), depending on $D_{c}$, but with a strong influence of wave-angle instability mechanism in any case.

While the morphodynamic instability hypothesis is very plausible, another possibility is that sand waves were forced by offshore bathymetric features. Off the Holmslands Tange coast there is a thin layer of mobile sand [Leth et al., 2004] and tidal and current 
sand waves have been documented [Anthony and Leth, 2002]. However, their wavelengths are an order of magnitude smaller than those of shoreline sand waves. Moreover, they migrate to the north whereas shoreline sand waves migrate to the south. Additionally, Anthony and Leth [2002] describes larger scale shoreface-connected ridges with a $3-4 \mathrm{~km}$ spacing but they seem to be stationary on a decadal time scale, again in contrast with the southward sand wave migration. Thus, it seems that offshore features should be excluded

as the primary cause of shoreline sand waves. This is also confirmed by the observed sea bed geology off the Danish west coast [Leth et al., 2004]. Similarly, the hypothesis that they were related to surf zone bars seems unlikely since Kaergaard et al. [2012] found little correlation between the shoreline undulations and the breaker bars. Thus, notwithstanding that other factors could have an influence or even could have provided the initial perturbation, we conclude that the sand waves would be primarily controlled by both wave-energy and wave-angle instability mechanisms.

\subsection{Limitations of the study}

The present linear stability analysis is very useful to explore the conditions and the mechanisms for shoreline instability. The linearity assumption seems reasonable since the amplitude of the observed shoreline undulations is very small (e.g., in comparison with their wavelength). However, even with this small amplitude the shape of the observed sand waves is neither sinusoidal nor constant, and migration at different rates and maybe wavelength coarsening are observed [Kaergaard et al., 2012]. It is therefore remarkable that, in spite of the linearity assumption, the analysis captures reasonably well the main characteristics of the Holmslands Tange sand waves. Another limitation is the one-line approximation, in which the response of the bathymetry to shoreline changes is instanta- 
neous. This poses an important problem because there are two different time-scales here: $T_{\ell}$ associated to the morphological changes driven by the longshore transport in the surf zone and $T_{c}$ associated to the time-scale at which the excess or deficit of sand in the surf zone is redistributed across the shoaling zone by cross-shore transport up to $D_{c}$. Since wave-angle instability mechanism needs a relatively large $D_{c}$, the $T_{c}$ scale tends to be large because the morphological changes at such large depth are slow [Ortiz and Ashton, 2016]. If $T_{c}$ is too large in comparison with $T_{\ell}$ detuning would happen with the result that the potential feedback mechanism could be inhibited.

Further research should also investigate the relevance of the large scale shoreline instability caused by the littoral drift from a more general geographical perspective. Other potential sites should be investigated. Model application would require a detailed data acquisition and analysis but, as far as we know, this is only available at present in the case of Holmslands Tange [Kaergaard et al., 2012]. In particular, we do not know whether conditions leading to low $\theta_{c}$ are very rare or not. Regarding the background bathymetric profile, a relatively steep surf zone (large $\beta_{s}$ ) seems at odds with a gently sloping shoreface (small $B$ ). But Holmslands Tange (see Figure 2) provides an example. More generally, this could occur on coarse sediment coasts with a steep surf zone where the slope is controlled by the grain size together with the wave climate whereas the shoreface profile has a substantially lower slope due to geological controls , e.g., antecedent geology or sediment availability. Regarding $D_{c}$, the wave-angle instability onset needs a minimum $D_{c}$ that depends on the other parameters but is typically quite large, $D_{c} \sim 10-20 \mathrm{~m}$. Nevertheless, it seems that these large values are realistic on some coasts.

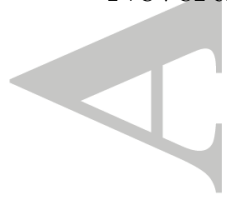




\section{Conclusions}

Alongshore undulating bathymetries cause alongshore gradients in wave refraction and shoaling hence gradients in littoral drift. The associated feedback mechanisms between waves and morphology through sediment transport have been investigated. There are two sources of positive feedback: the gradients in wave energy and the gradients in relative wave incidence angle. When the wavelength of the features is large, gradients in wave energy nearly always create a positive feedback while gradients in wave angle typically cause a negative feedback. However, for gently sloping shorefaces with relatively steep surf zones, for large enough depths of closure and large enough wavelengths, the feedback originated by the wave angle can be positive too. In the situations where both feedbacks are positive, sandwaves can emerge for any wave angle, the scenario first described by Idier et al. [2011]. When the gradients in wave angle are stabilizing, opposing the destabilizing effect of the energy gradients, which effect is dominant depends on the angle: for low angles, the gradients in the angle dominate, while the energy gradients dominate for high angles. This competition leads to a critical angle $\theta_{c}$ above which sand waves develop, the scenario first studied by Ashton et al. [2001]. These two scenarios have been termed LAWI (Low-angle wave instability) and HAWI (High-angle wave instability) due to the existence or not of a critical angle. However, from the point of view of the involved physical mechanisms, there is not a clear distinction between them, but they come out of the interplay of the same processes for different parameter values. Therefore, the term 'km-scale littoral drift induced instability' would be more appropriate.

To test the instability mechanisms in nature, the linear stability model has been applied

to Srd. Holmslands Tange (Denmark), where small amplitude shoreline sand waves of 
$5-6 \mathrm{~km}$ wavelength migrating to the south at $0.46 \pm 0.29 \mathrm{~km} / \mathrm{yr}$ are observed. According to our general analysis, once the bathymetric profile and the wave conditions are given, the results depend on the depth of closure, $D_{c}$. Based on both observations and the wave climate we have estimated $D_{c} \simeq 9-13 \mathrm{~m}$ and we have forced the model with the wave time series measured at station 2031, which is $70 \mathrm{~km}$ north of Holmslands Tange, during 2010-14. If $D_{c} \geq 9.2 \mathrm{~m}$, the model predicts the formation of sand waves with a wavelength and a migration celerity reasonably close to observations. Although there are no measurements of the characteristic growth time, the model one is in the right order of magnitude. These results are in contrast with Kaergaard and Fredsoe [2013a] who found that this coast is stable under the littoral drift. The main reason for the difference is the depth of closure they considered, $D_{c}=5 \mathrm{~m}$. We have done sensitivity analysis with constant mean wave conditions and it is found that our model results are still roughly consistent with observations if $H, T, \theta$ are varied within the ranges $1.6-2 \mathrm{~m}, 5-7 \mathrm{~s}$ and $32-52^{\circ}$, respectively. However, below $D_{c}=7.4 \mathrm{~m}$ and for $\theta=42^{\circ}$ the coast would be stable, which is consistent with the results of Kaergaard and Fredsoe [2013a]. We find that a value $D_{c}=12 \mathrm{~m}$ would make the Holmslands Tange coast to be nearly at the threshold for HAWI/LAWI, i.e., for smaller values there would be a critical angle whereas for larger values there would not. Thus, both the alongshore gradients in wave energy and in wave angle would contribute to the feedback driving the observed sand waves.

\section{Appendix A: Computation of the intensity of the perturbation in wave refraction}

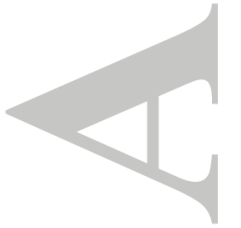

(C)2017 American Geophysical Union. All Rights Reserved. 
Essential to the 1D-morfo model is the computation of perturbed wave refraction over the undulating depth contours associated to a small amplitude sand wave of the form

$$
y_{s}(x)=\frac{A}{2} e^{i K x}+\text { c.c. }
$$

with wavelength $L=2 \pi / K$, where $x$ is the coordinate along the mean shoreline and $y_{s}(x)$ is the cross-shore position of the perturbed shoreline. This is briefly presented in the Appendix A of Falqués and Calvete [2005]. The perturbed wavenumber and wave angle are assumed to be of the form

$$
k(x, y)=k_{0}(y)+\hat{k}^{\prime}(y) e^{i K x}+c . c ., \quad \theta(x, y)=\theta_{0}(y)+\hat{\theta}^{\prime}(y) e^{i K x}+\text { c.c. }
$$

where $k_{0}(y)$ and $\theta_{0}(y)$ are the unperturbed wavenumber and wave angle. Their perturbations are given by $\hat{k}^{\prime}(y)$ and $\hat{\theta}^{\prime}(y)$, which are complex, the phase giving the alongshore lag with respect to the sand wave crest. How the intensity of the perturbation in wave angle depends on the beach profile and on $D_{c}$ can be more easily understood in case of normal wave incidence, $\theta_{0}(y)=0$, and this gives a clue into understanding the model results in the general case. In this case, combining equations (A2) and (A3) of Falqués and Calvete [2005] and using the unperturbed water depth $D$ as independent variable instead of $y$ gives

$$
\beta(D) \frac{d}{d D}\left(k_{0}(D) \hat{\theta}^{\prime}(D)\right)=-i K \zeta(p(D)) k_{0}(D) \frac{\hat{h}(D)}{D}
$$

where $\beta(D)=d D / d y$. We define $p(D)=D k_{0}(D)$ and $\zeta(p)=2 p /(2 p+\sinh (2 p))$ where, according to the dispersion relation and for a given wave period, the unperturbed wave number is a function of the depth only, $k_{0}(D)$. The cross-shore shape of the bathymetric perturbation is assumed to be real (no phase lag with respect to shoreline undulation) 
and linear in $D$, so that

$$
\hat{h}(x)=A \beta_{s}\left(1-\left(\frac{D}{D_{c}}\right)^{3 / 2}\right) \quad \text { for } \quad D \leq D_{c}
$$

and $\hat{h}(x)=0$ beyond $D_{c}$ (this has been assumed for the model computations). The magnitude of the perturbation in angle at breaking, $\theta_{b}^{\prime}$, is then obtained by integration between the breaking line, $D_{b}$, and $D_{c}$ :

$$
\theta_{b}^{\prime}=K \int_{D_{b}}^{D_{c}} \zeta(p(D)) \frac{k_{0}(D)}{k_{b} D} \frac{\hat{h}(D)}{\beta(D)} d D=K \int_{D_{b}}^{D_{c}} F(D) d D
$$

where the function to integrate is positive, $F(D)>0$ (notice that $F(D)$ depends on $A, \beta_{s}, D_{c}, B$ because $\hat{h}$ and $\beta$ depend on them, according to equations (4) and (A4)). Now, for a given $A$, if $\beta_{s}$ and $B$ are held constant and $D_{c}$ is increased, $\hat{h}(D)$ increases for each $D$ (equation A4) hence $F(D)$ increases. Moreover, the integration interval is wider and, therefore, $\theta_{b}^{\prime}$ increases. Now, for a given $A$, if $\beta_{s}, D_{c}$ are held constant and $B$ is decreased, $\hat{h}(D)$ does not change while $\beta(D)$ has a lower value for each $D$ (equation 4 ). As a result, $\theta_{b}^{\prime}$ increases. Notice that $D_{b}$ does not change as it depends only on the wave height. Finally, if $D_{c}$ and $B$ are held constant and $\beta_{s}$ is increased, for a given $A, A \beta_{s}$ will be larger and so will be the $\hat{h}(D)$ function (equation A4). The perturbation $\theta_{b}^{\prime}$ will therefore increase. It is true that the slope $\beta(D)$ will increase near the shoreline but this effect is significant only very close to shore. For example if $\beta_{s}$ increases by a factor 2 the $\hat{h}(D)$ will be multiplied by 2 uniformly over all the domain, $D_{b}<D<D_{c}$. Instead, $\beta(D)$ will be multiplied by 2 only very close to the shore and will keep almost the same value for $D>D_{b}$.

\section{Acknowledgments.}

(C)2017 American Geophysical Union. All Rights Reserved. 
Data are available via e-mail to the corresponding author. This research is part of the projects CTM2012-35398 and CTM2015-66225-C2-1-P funded by the Spanish Government and cofounded by the E.U. (FEDER). It has also been funded by the MORLO2C and ShorelineSW projects (BRGM). The fourth author is funded by the Mexican Government (CONACyT, grant number 217754). We warmly thank Fabrice Ardhuin, Aart Kroon and Kasper Kaergaard for providing the global wave model results, the wave conditions

at station 2031 of the Danish Coastal Authorities and bathymetric data from Holmslands Tange, respectively. Andrew Ashton, Kasper Kaergaard and a third anonymous referee are also gratefully acknowledged for their thorough review and useful advice.

\section{References}

Anthony, D., and J. O. Leth (2002), Large-scale bedforms, sediment distribution and sand mobility in the eastern north sea of the danish west coast, Marine Geology, 182, $247-263$.

Ashton, A., and A. B. Murray (2006a), High-angle wave instability and emergent shoreline shapes: 2. Wave climate analysis and comparisons to nature, J.Geophys.Res., 111, F04,012,doi:10.1029/2005JF000,423.

Ashton, A., and A. B. Murray (2006b), High-angle wave instability and emergent shoreline shapes: 1. Modeling of sand waves, flying spits, and capes, J.Geophys.Res., 111, F04,011,doi:10.1029/2005JF000,422.

Ashton, A., A. B. Murray, and O. Arnault (2001), Formation of coastline features by large-scale instabilities induced by high-angle waves, Nature, 414, 296-300. 
Bender, C. J., and R. G. Dean (2004), Potential shoreline changes induced by threedimentional bathymetric anomalies with gradual transitions in depth, Coast. Eng., 51, $1143-1161$.

Birkemeier, W. A. (1985), Field data on seaward limit of profile change, J. Waterway, Port, Coastal and Ocean Eng., ASCE, $111(3)$, 598-602.

Christensen, E. D., A. Skou, I. Broker, M. Rubjerg, and P. Sorensen (2001), Sediment transport along the west coast of Jutland, in Proc. of the 12th Biennial Coastal Zone Conference, Cleveland, OH, pp. 1-5.

Falqués, A. (2006), Wave driven alongshore sediment transport and stability of the Dutch coastline, Coastal Eng., 53, 243-254.

Falqués, A., and D. Calvete (2005), Large scale dynamics of sandy coastlines. Diffusivity and instability, J. Geophys. Res., 110(C03007), doi:10.1029/2004JC002587.

Falqués, A., D. Calvete, and F. Ribas (2011), Shoreline instability due to very oblique wave incidence: Some remarks on the physics, J. Coastal Res., 27(2), 291-295.

Hallermeier, R. J. (1978), Uses for a calculated limit depth to beach erosion, in Coastal Eng. 1978, pp. 1493-1512, Am. Soc. of Civ. Eng.

Hinton, C., and R. J. Nicholls (1998), Spatial and temporal behaviour of depth of closure along the Holland coast, in Coastal Eng. 1998, edited by ASCE, pp. 2913-2925.

Idier, D., and A. Falqués (2014), How kilometric sandy shoreline undulations correlate with wave and morphology characteristics: preliminary analysis on the Atlantic coast of Africa, Advances in Geosciences, 39, 55-60, doi:10.5194/adgeo-39-55-2014.

Idier, D., A. Falqués, B. G. Ruessink, and R. Garnier (2011), Shoreline instability under low-angle wave incidence, J. Geophys. Res., 116(F04031), doi:10.1029/2010JF001894. 
Kaergaard, K. (2011), Numerical modeling of shoreline undulations, Ph.D. thesis, DTU Mechanical Engineering, Denmark.

Kaergaard, K., and J. Fredsoe (2013a), Numerical modeling of shoreline undulations part 2: Varying wave climate and comparison with observations, Coastal Eng., 75, 77-90.

Kaergaard, K., and J. Fredsoe (2013b), Numerical modeling of shoreline undulations part 1: Constant wave climate, Coastal Eng., 75, 64-76.

Kaergaard, K., J. Fredsoe, and S. B. Knudsen (2012), Coastline undulations on the West Coast of Denmark: Offshore extent, relation to breaker bars and transported sediment volume, Coastal Eng., 60, 109-122.

Komar, P. D. (1998), Beach Processes and Sedimentation, second ed., Prentice Hall, Englewood Cliffs, N.J.

Leont'ev, I. O., D. V. Ryabchuk, A. Y. Sergeev, and L. L. Sukhacheva (2011), On the genesis of some bottom and coastal features in the Eastern Gulf of Finland, Oceanology, $51(4), 688-698$.

Leth, J. O., B. Larsen, and D. Anthony (2004), Sediment distribution and transport in the shallow coastal waters along the west coast of denmark, Geological Survey of Denmark and Greenland Bulletin, 4, 4144.

Marsh, S. W., R. J. Nicholls, A. Kroon, and P. Hoekstra (1998), Assessment of depth of closure on a nourished beach: Terschelling, the Netherlands, in Coastal Eng. 1998, edited by ASCE, pp. 3110-3123.

McNinch, J. E. (2004), Geologic control in the nearshore: shore-oblique sandbars and shoreline erosional hotspots, mid-atlantic bight, usa, Mar. Geology, 211(1), 121-141. 
Medellín, G., A. Falqués, R. Medina, and M. González (2009), Sand waves on a lowenergy beach at 'El Puntal' spit, Spain: Linear Stability Analysis, J. Geophys. Res., 114(C03022), doi:10.1029/2007JC004426.

Nicholls, R. J., M. Larson, M. Capobianco, and W. A. Birkemeier (1998), Depth of closure: improving understanding and prediction, in Coastal Eng. 1998, edited by ASCE, pp. $2888-2901$.

Ortega-Sánchez, M., F. J. Lobo, A. López-Ruiz, M. A. Losada, and L. M. Fernández-Salas (2014), The influence of shelf-indenting canyons and infralittoral prograding wedges on coastal morphology: The Carchuna system in Southern Spain, Mar. Geol., 347, 107-122.

Ortiz, A. C., and A. D. Ashton (2016), Exploring shoreface dynamics and a mechanistic explanation for a morphodynamic depth of closure, J. Geophys. Res. Earth Surf, 121, 442464, doi:10.1002/2015JF003699.

Rasele, N., and F. Ardhuin (2013), A global wave parameter database for geophysical applications. part 2: Model validation with improved source term parameterization, Ocean Modeling, 70(10), doi:10.1016/j.ocemod.2012.12.001.

Ribas, F., A. Falqués, N. van den Berg, and M. Caballeria (2013), Modelling shoreline sand waves on the coasts of Namibia and Angola, Int. J. Sediment Res., 28(3), 1-11.

Short, A. D. (1999), Handbook of Beach and Shoreface Morphodynamics, Wiley, Chichester.

Tolman, H. L., M. L. Banner, and J. M. Kaihatu (2013), The NOPP operational wave model improvement project, Ocean Modeling, 70, 2-10, doi:10.1016/j.ocemod.2012.11.011. 
Uguccioni, L., R. Deigaard, and J. Fredsoe (2006), Instability of a coastline with very oblique wave incidence, in Coastal Eng. 2006, pp. 3542-3553, World Scientific.

Valvo, L. M., A. B. Murray, and A. Ashton (2006), How does underlaying geology affect shoreline change? An initial model investigation, J. Geophys. Res. Earth Surf., 111 (F02025), doi:10.1029/2005JF000340.

van den Berg, N., A. Falqués, and F. Ribas (2012), Modelling large scale shoreline sand waves under oblique wave incidence, J. Geophys. Res., 117(F03019), doi:10.1029/2011JF002177.

van den Berg, N., A. Falqués, F. Ribas, and M. Caballeria (2014), On the wavelength of self-organized shoreline sand waves, J. Geophys. Res. Earth Surf., 119, 665-681, doi:10.1002/2013JF002751.

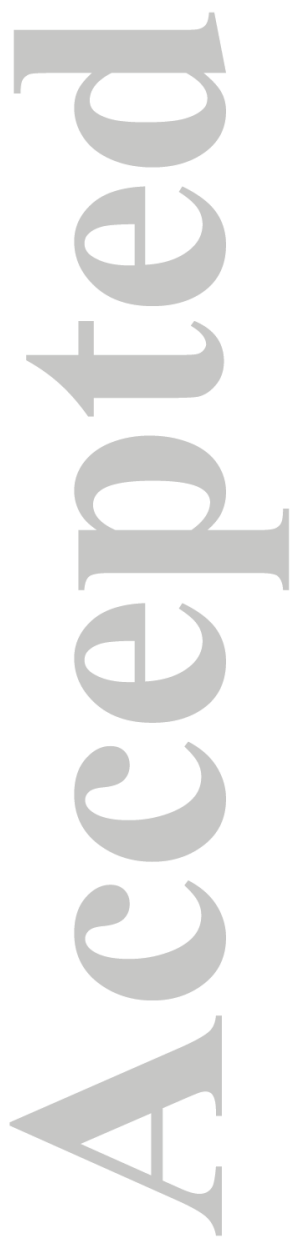



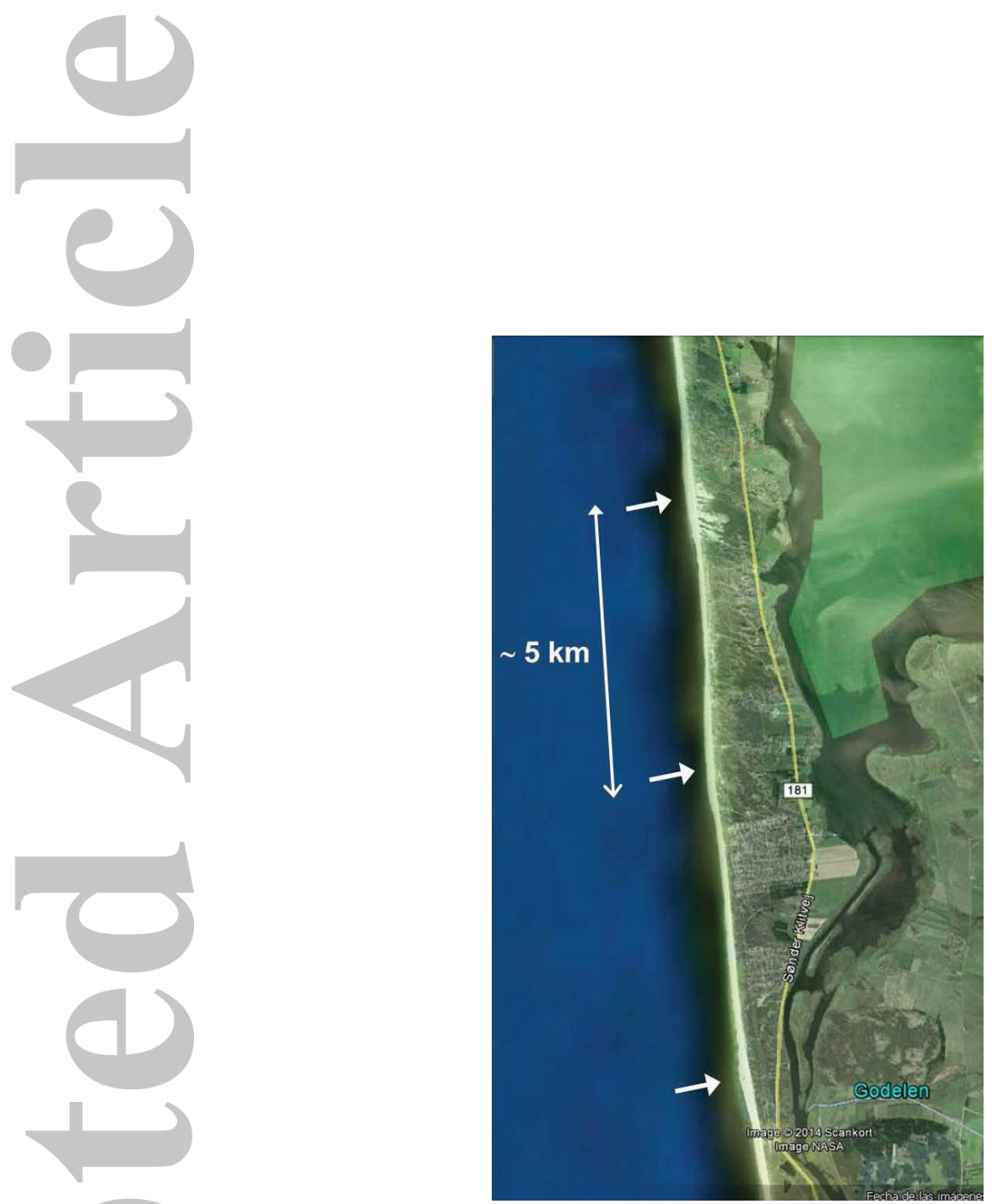

Figure 1. Shoreline of the Holmslands Tange coast, Denmark (source: Google Earth, image from 2014 Scankort and NASA). The shoreline undulations can be seen, the arrows showing the crests. The geographical coordinates at the center are Lat $=55^{\circ} 50^{\prime} 04^{\prime \prime} \mathrm{N}, \mathrm{Long}=8^{\circ} 09^{\prime} 18^{\prime \prime} \mathrm{E}$.

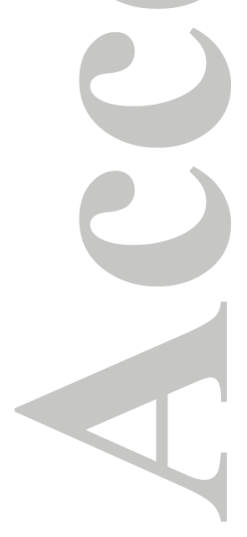

(C)2017 American Geophysical Union. All Rights Reserved. 

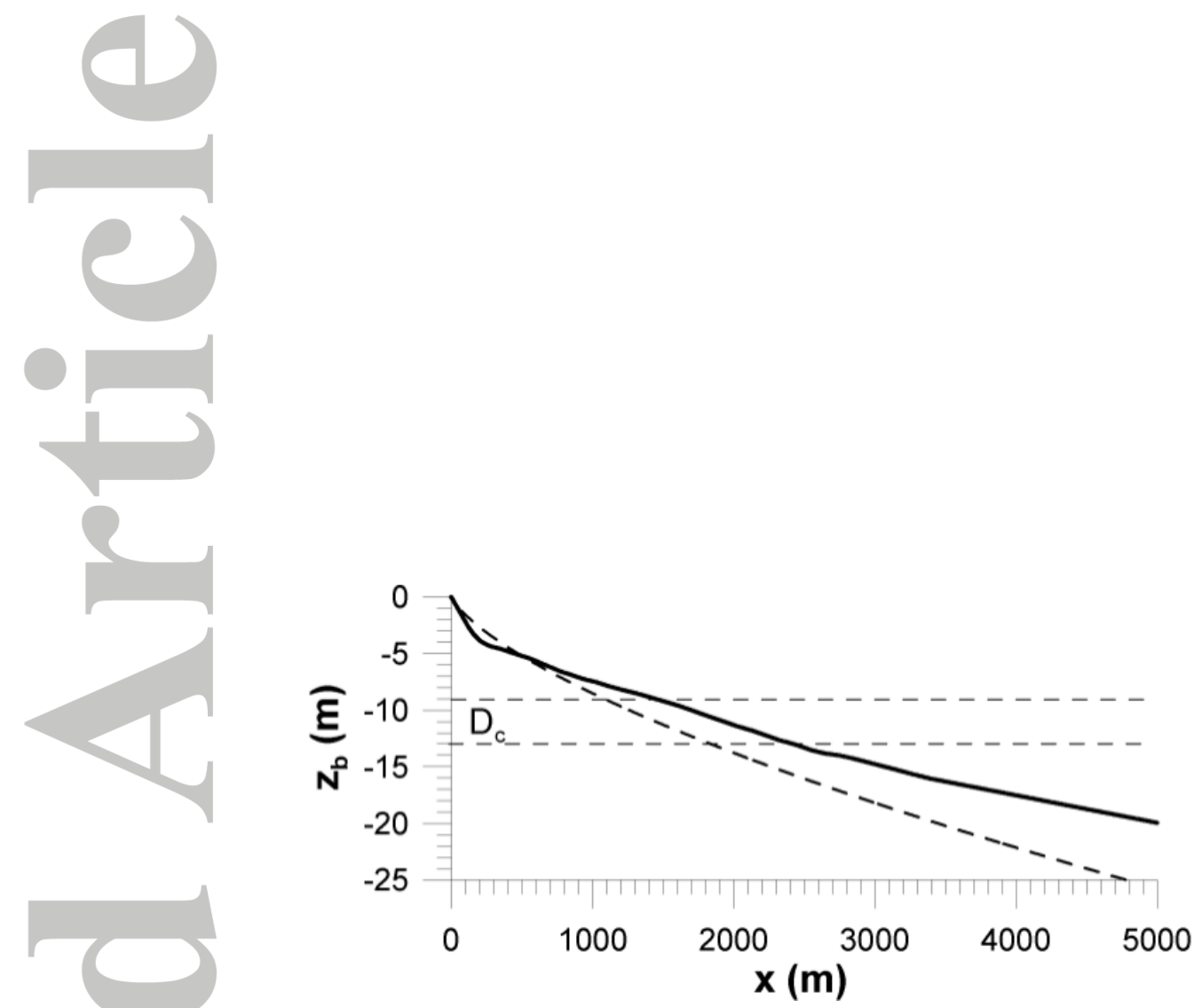

Figure 2. Background beach profile representative of the mean profile observed at Holmslands Tange, according to Kaergaard [2011] (solid line). The shifted Dean-type profile with $\beta_{s}=0.023$ and $B=0.09 \mathrm{~m}^{1 / 3}$, approximating the observed one, is represented (dashed line). The estimated range for the depth of closure, $D_{c}$, (see section 5.2) is also indicated. 


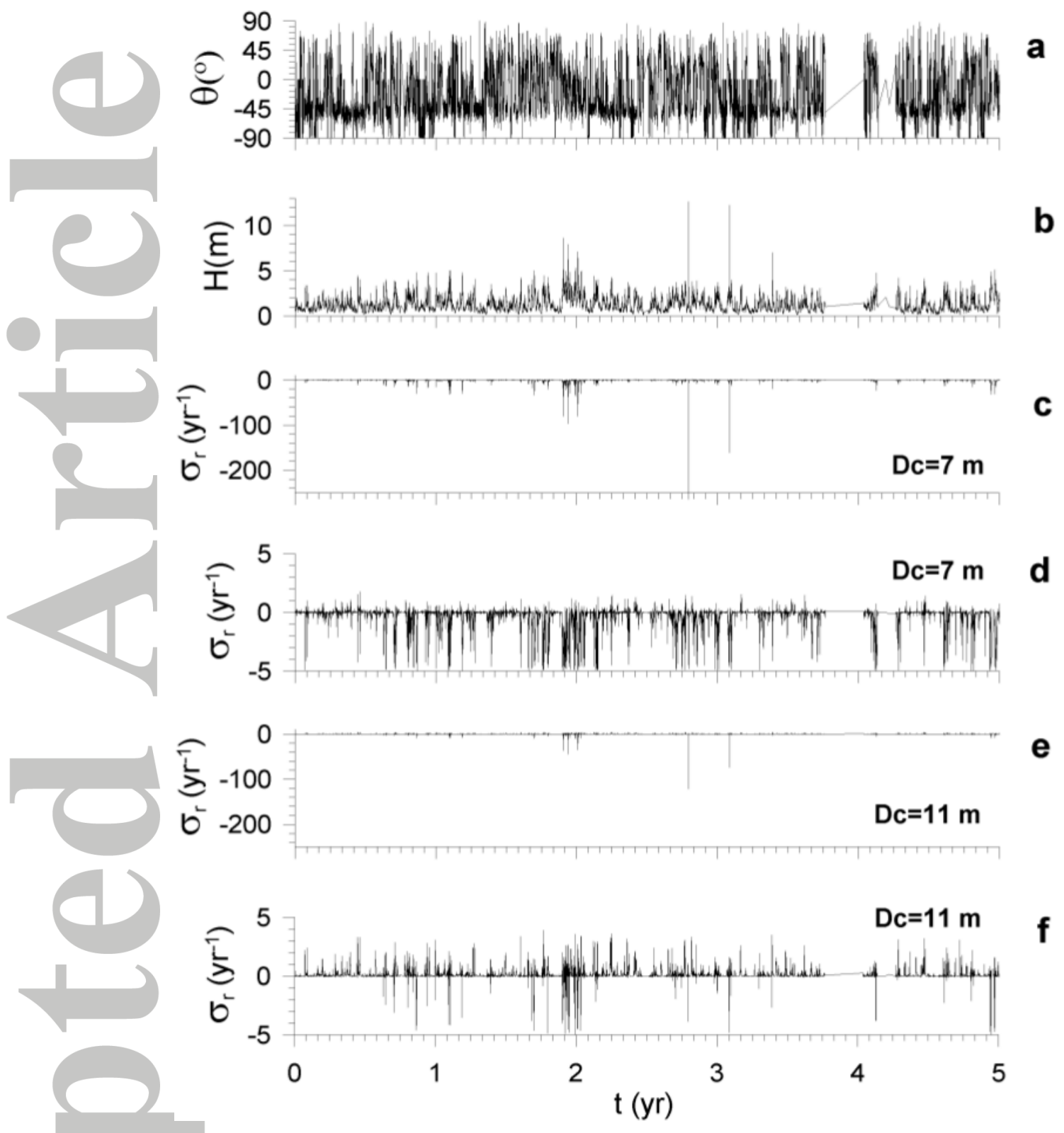

Figure 3. Time series of $\theta$ (with respect to the shore-normal at Holmslands Tange, positive values indicating waves from SW) (a) and $\mathrm{H}$ (b) from station 2031 at the west Danish coast from 01/2010 to $12 / 2014$. Panels (c) and (e) show the corresponding time series of hourly real growth rates of a sand wave with $L=6 \mathrm{~km}$ for $D_{c}=7 \mathrm{~m}$ and for $D_{c}=11 \mathrm{~m}$, respectively. Panels (d) and (f) show zooms of (c) and (e), where the positive values can be seen more clearly.

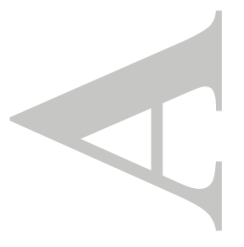

(C)2017 American Geophysical Union. All Rights Reserved. 


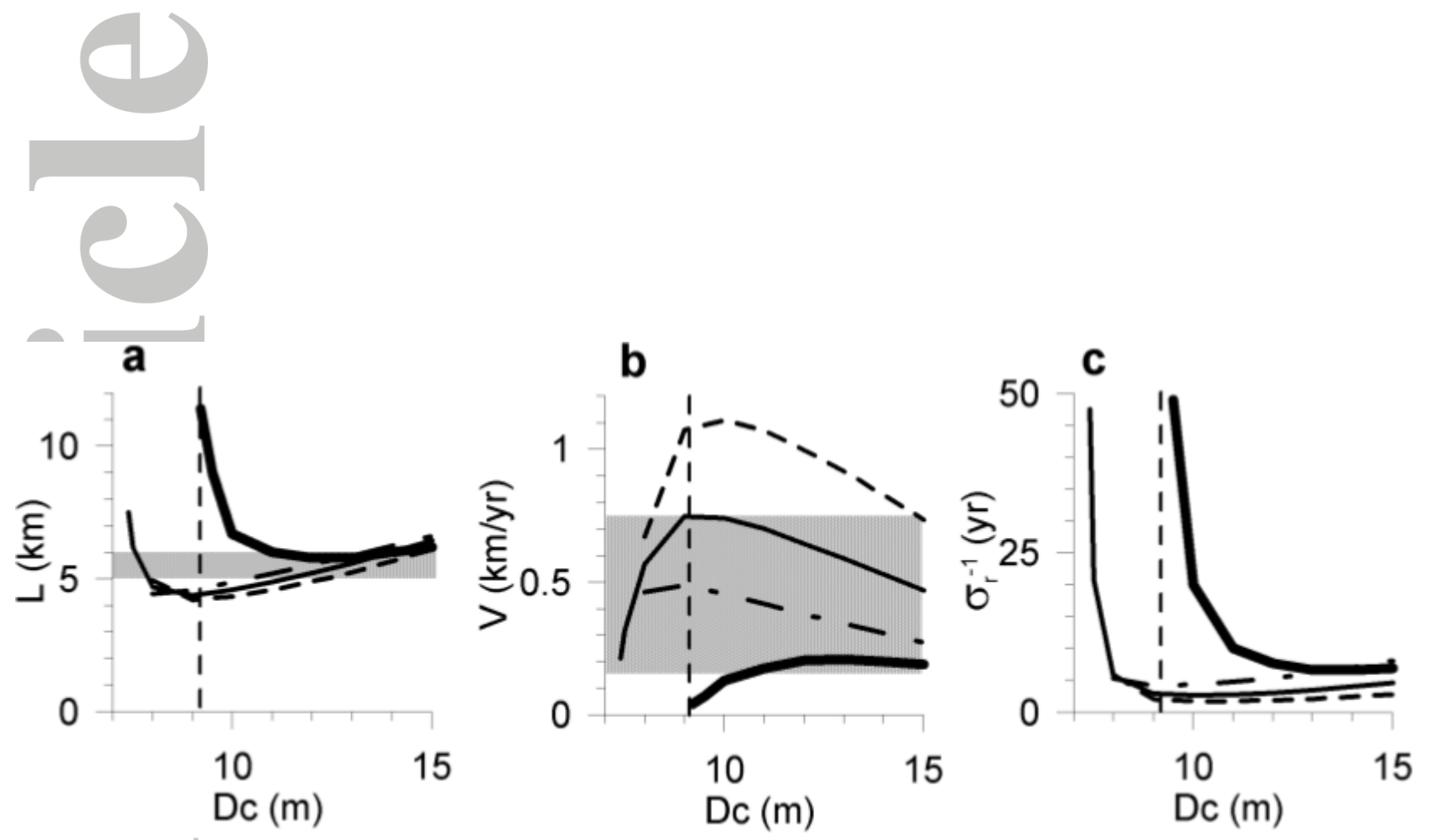

Figure 4. Most amplified wavelength, $L$ (a), and its corresponding alongshore celerity, $V(\mathrm{~b})$, and growth time, $\sigma_{r}^{-1}(\mathrm{c})$, for the stability analysis of Holmslands Tange case as a function of the depth of closure, $D_{c}$. The thick solid lines correspond to the computations with the time series of wave parameters and the thin solid lines correspond to the mean (weighted) wave conditions observed on that coast, $H=1.8 \mathrm{~m}, T=6.1 \mathrm{~s}$ and $\theta=42^{\circ}$ at $D=25 \mathrm{~m}$. The other two dashed lines indicate the uncertainty degree in the results for mean wave conditions. The vertical dashed lines indicate the critical $D_{c}$ value below which there is no instability for the time series of wave parameters. The shadowed regions correspond to the observations by Kaergaard et al. [2012]. 
a

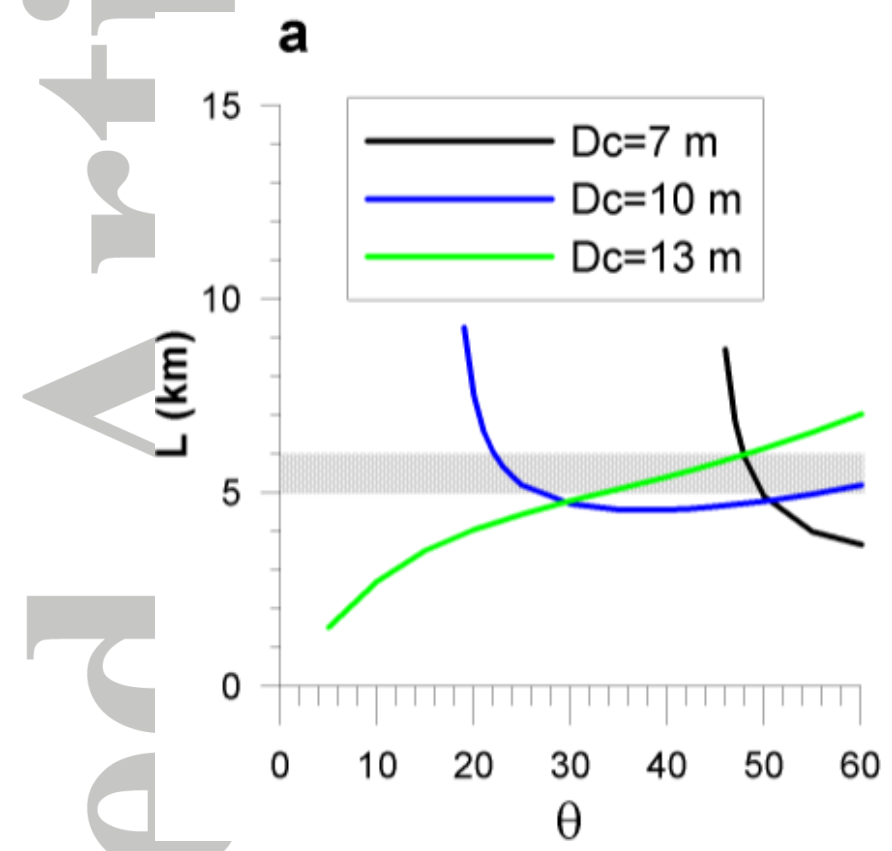

b

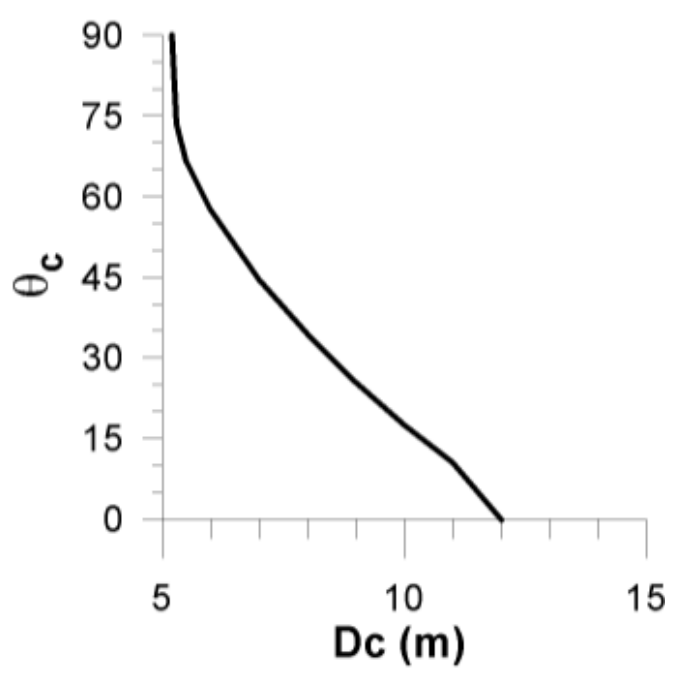

Figure 5. Sensitivity to the wave angle of the stability analysis for Holmslands Tange for constant mean wave conditions. Panel a): most amplified wavelength, $L$, as a function of the wave angle, $\theta$, and the depth of closure, $D_{c}$. Panel b): critical wave angle for instability, $\theta_{c}$, as a function of $D_{c}$. The mean wave height and period are the same as in Figure 4 and the shadowed region corresponds to the observations by Kaergaard et al. [2012].

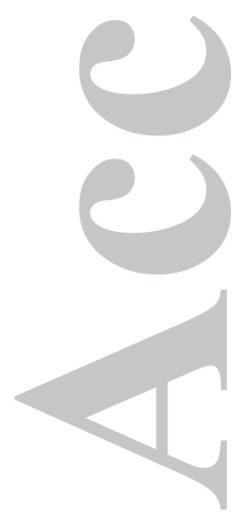




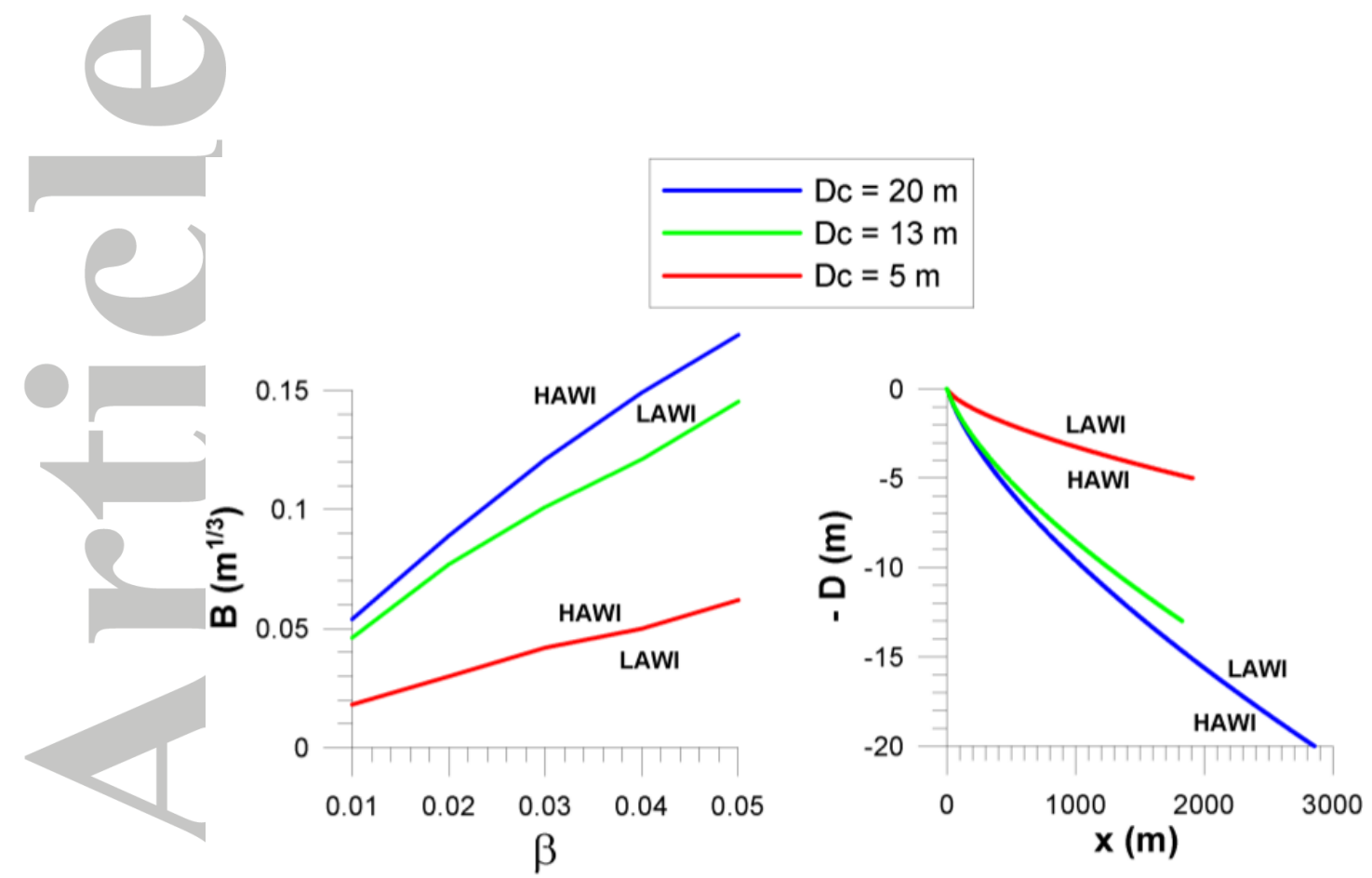

Figure 6. Left panel: Transition lines between HAWI and LAWI regimes as a function of $D_{c}$ and the cross-shore beach profile, defined by $\beta_{s}$ and $B$. Each line corresponds to a $D_{c}$ value. The region above each line to the left corresponds to HAWI regime while the region below it to the right corresponds to LAWI regime. Right panel: Transition cross-shore beach profiles between HAWI and LAWI regimes as a function of $D_{c}$. For each line, the steeper profiles (i.e. larger $B)$ are in the HAWI regime whereas the milder ones (i.e. smaller $B$ ) are in the LAWI regime. The three transition profiles correspond to $\beta_{s}=0.023$ and $B=0.033 \mathrm{~m}^{1 / 3}$ (for $\left.D_{c}=5 \mathrm{~m}\right)$, $B=0.085 \mathrm{~m}^{1 / 3}$ (for $D_{c}=13 \mathrm{~m}$ ), and $B=0.101 \mathrm{~m}^{1 / 3}$ (for $D_{c}=20 \mathrm{~m}$ ). The transition profile for $D_{c}=13 \mathrm{~m}\left(B=0.085 \mathrm{~m}^{1 / 3}\right)$ corresponds approximately to the profile at Holmslands Tange ( $B=0.09 \mathrm{~m}^{1 / 3}$ according to Kaergaard and Fredsoe [2013a]). The wave conditions in both panels are $H=1.8 \mathrm{~m}, T=6.1 \mathrm{~s}$ and $\theta=42^{\circ}$ at $D=25 \mathrm{~m}$.

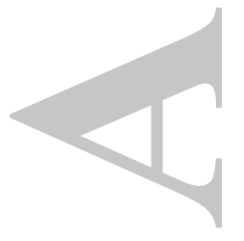

(C)2017 American Geophysical Union. All Rights Reserved. 


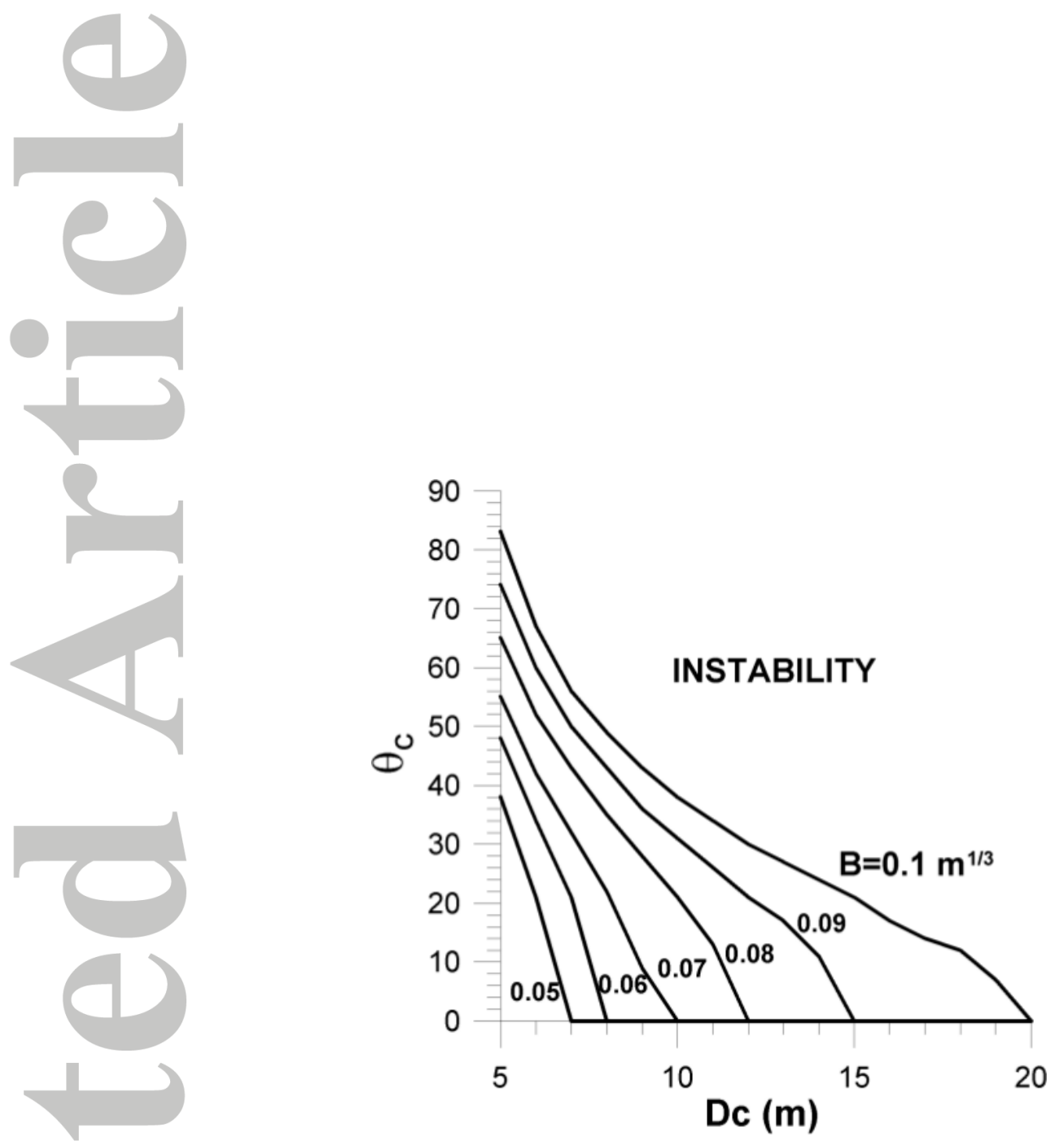

Figure 7. Critical angle, $\theta_{c}$, for shoreline instability as a function of $B$ and $D_{c}$ for $\beta_{s}=0.023$. Wave conditions as in Figure 6.

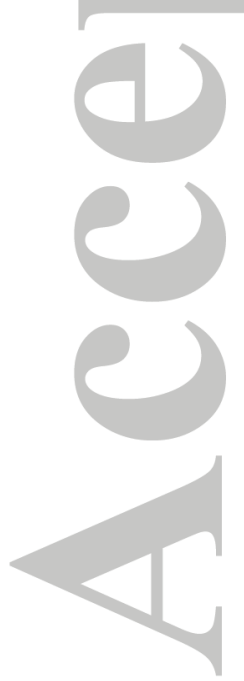




\section{$\mathrm{X}_{\mathrm{Q}}$ location giving growth/migration}

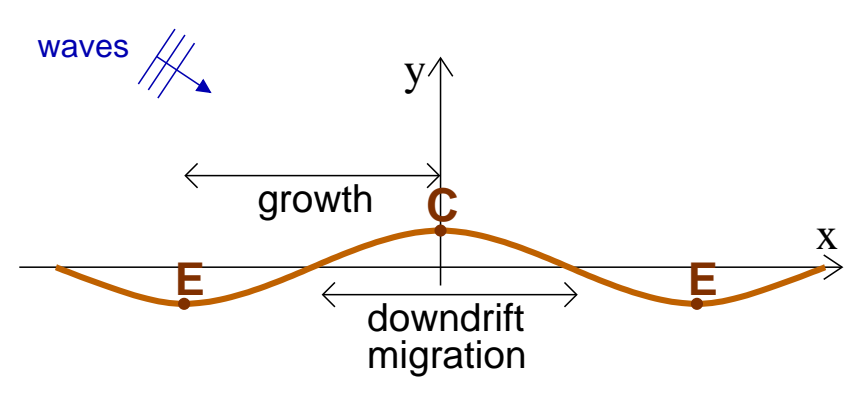

Figure 8. Growth and downdrift migration as a function of the position of the maximum in the longshore transport, $x_{Q}$. If this maximum is within the region "growth" the sand wave grows. If the maximum is within the region "downdrift migration" the sand wave migrates downdrift. A sand wave crest is indicated by "C" $(x=0)$ and the adjacent up and down-drift embayments are indicated by "E". The wavelength is the distance between the two embayments. 


$$
\mathrm{Q}=\mu \mathrm{H}_{\mathrm{b}}^{5 / 2} \sin \left(2 \alpha_{\mathrm{b}}\right)
$$

\section{a) Wave-energy instability mechanism:}

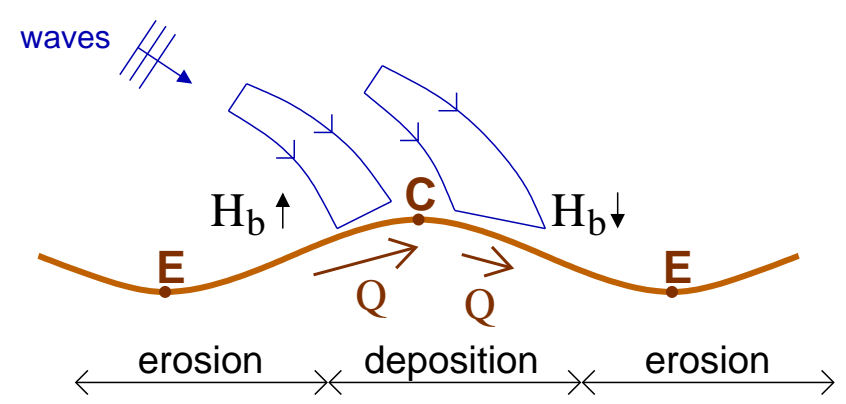

\section{b) Wave-angle instability mechanism:}
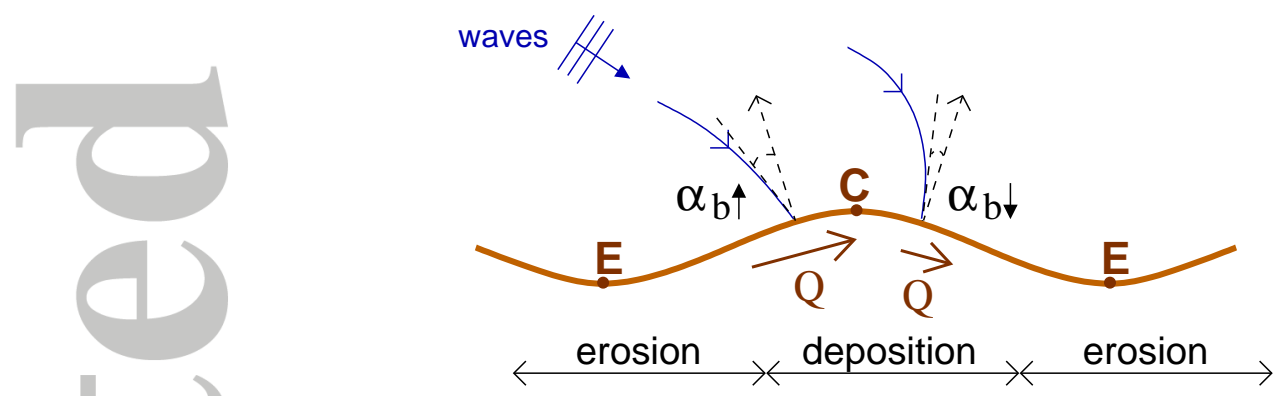

Figure 9. Sketch of the wave-energy (a) and the wave-angle (b) instability mechanisms. A sand wave crest is indicated by "C" and the up and down-drift embayments are indicated by "E". The different wave crest stretching and wave refraction at both flanks of the sand wave are indicated in panels a) and b), respectively. The differences caused on the sediment transport rate $Q$ are indicated by arrows. These gradients result in sand deposition at the crest and erosion at the embayments.

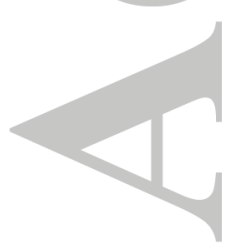


a) Stable regime

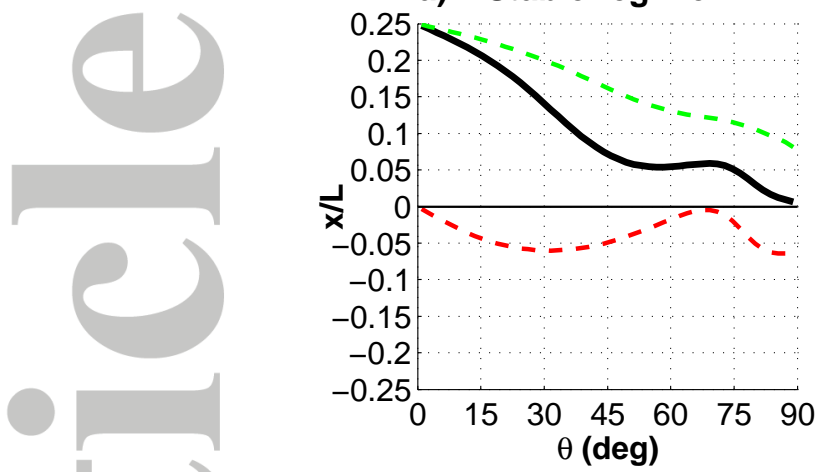

c) HAWI regime
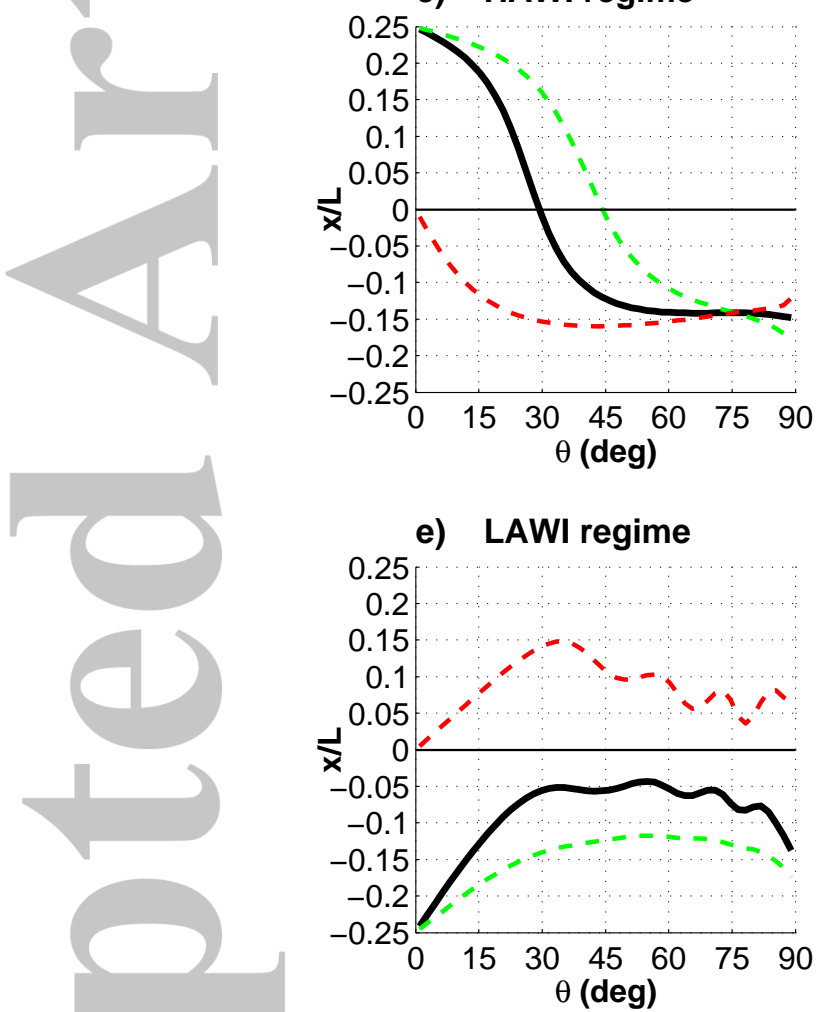

b) HAWI regime

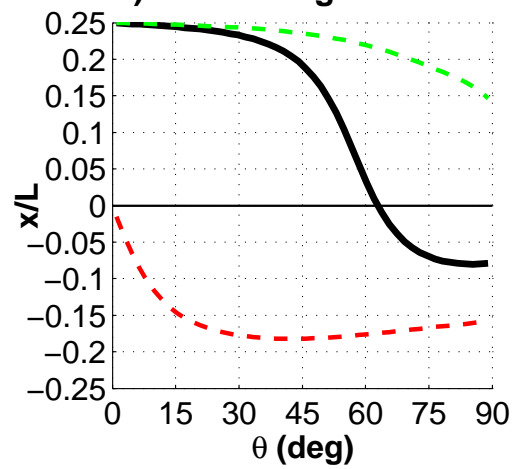

d) LAWI regime
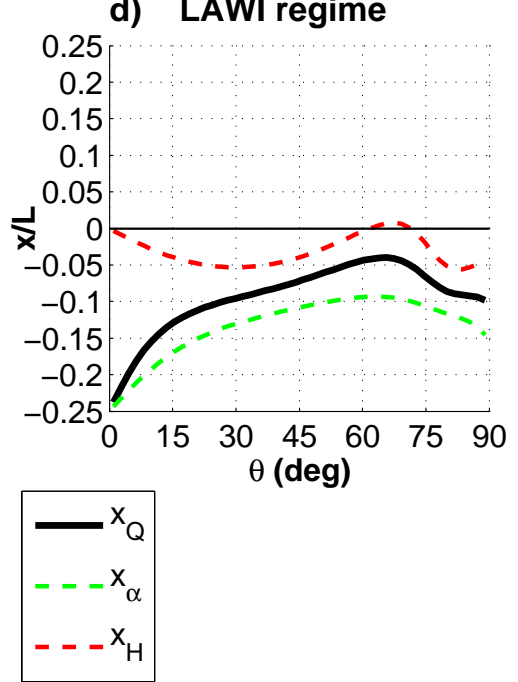

Figure 10. Relative (to wavelength) alongshore positions of the maxima in sediment transport, $x_{Q}$, in relative wave angle, $x_{\alpha}$, and in wave height, $x_{H}$, as a function of offshore wave angle, $\theta$, for $H=1.8 \mathrm{~m}$ and $L=5800 \mathrm{~m}$. The profile parameters and $D_{c}$ are equal to a) $\beta_{s}=0.010$, $B=0.09 \mathrm{~m}^{1 / 3}$ and $\left.D_{c}=20 \mathrm{~m}, \mathrm{~b}\right) \beta_{s}=0.010, B=0.07 \mathrm{~m}^{1 / 3}$ and $\left.D_{c}=7 \mathrm{~m}, \mathrm{c}\right) \beta_{s}=0.023$, $B=0.09 \mathrm{~m}^{1 / 3}$ and $\left.D_{c}=10 \mathrm{~m}, \mathrm{~d}\right) \beta_{s}=0.023, B=0.09 \mathrm{~m}^{1 / 3}$ and $D_{c}=20 \mathrm{~m}$, and e) $\beta_{s}=0.023$, $B=0.044 \mathrm{~m}^{1 / 3}$ and $D_{c}=20 \mathrm{~m}$. The wave period is $T=6.1 \mathrm{~s}$ for all plots, except $T=5.1 \mathrm{~s}$ for panel e). 
a) Pure-HAWI regime

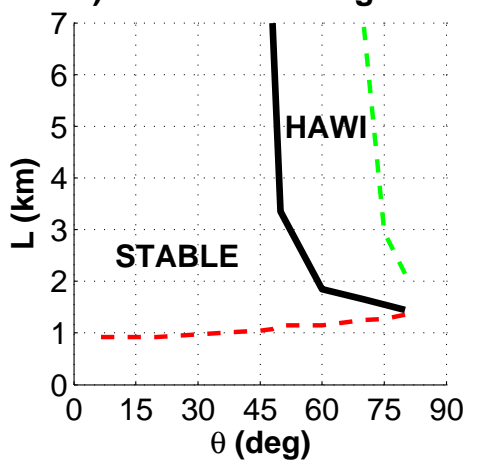

c) LAWI regime

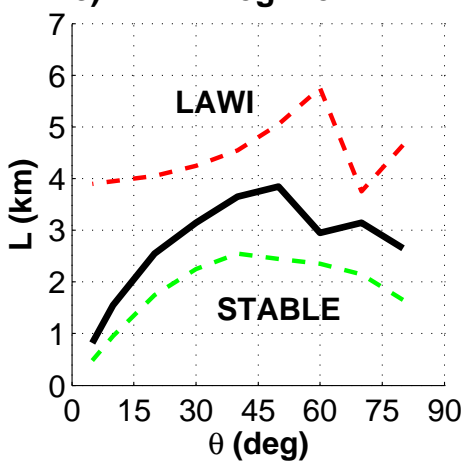
$\theta$ (deg) b) Mixed-HAWI regime

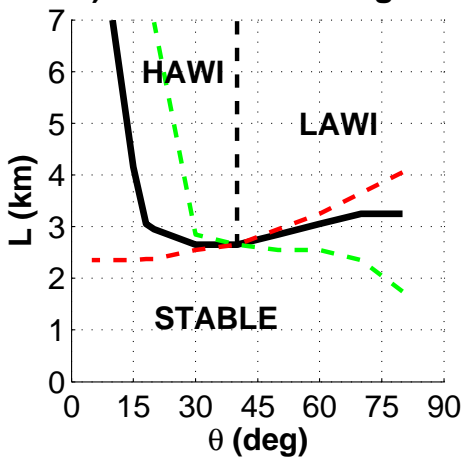

- overall instability transition

- - - wave-angle instability transition

- - - wave-energy instability transition

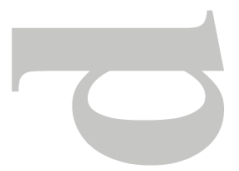

(7)

Figure 11. Transition curves for the onset of wave-energy instability (dashed-green), waveangle instability (dashed-red) and resulting overall instability (solid-black), as a function of wavelength, $L$, and wave angle, $\theta$, for the beach profile corresponding to Holmslands Tange $\left(\beta_{s}=0.023\right.$ and $\left.B=0.09 \mathrm{~m}^{1 / 3}\right)$, and for wave conditions $H=1.8 \mathrm{~m}$ and $T=6.1 \mathrm{~s}$ at $D=25 \mathrm{~m}$. The three panels correspond to: a) $D_{c}=7 \mathrm{~m}$ (Pure-HAWI regime), b) $D_{c}=13 \mathrm{~m}$ (Mixed-HAWI regime), and c) $D_{c}=20 \mathrm{~m}$ (LAWI regime). In panels a) and b), the regions above/to the right (below/to the left) correspond to instability (stability). In panel c), the regions above (below) each line correspond to instability (stability).

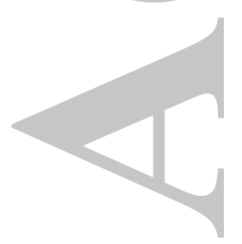

